\title{
ANTIGENS AND IMMUNOEVASINS: OPPONENTS IN CYTOMEGALOVIRUS IMMUNE SURVEILLANCE
}

\section{Matthias J. Reddehase}

CD8 ${ }^{+} \mathrm{T}$ cells are the main effector cells for the immune control of cytomegaloviruses. To subvert this control, human and mouse cytomegaloviruses each encode a set of immune-evasion proteins, referred to here as immunoevasins, which interfere specifically with the MHC class I pathway of antigen processing and presentation. Although the concerted action of immunoevasins prevents the presentation of certain viral peptides, other viral peptides escape this blockade conditionally or constitutively and thereby provide the molecular basis of immune surveillance by $\mathrm{CD}^{+} \mathrm{T}$ cells. The definition of viral antigenic peptides that are presented despite the presence of immunoevasins adds a further dimension to the prediction of protective epitopes for use in vaccines.

Human herpesvirus 5 (HHV5), better known as human cytomegalovirus (hCMV), is the prototype member of the subfamily $\beta$-Herpesvirinae of the fam-

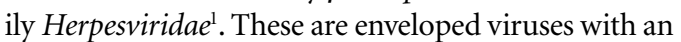
icosahedral capsid that encloses a double-stranded, linear DNA genome. The genome has a high proteincoding capacity and is able theoretically to encode tens of thousands of potentially antigenic peptides. The members of this subfamily are highly adapted to their mammalian hosts and are host-species specific in their replication (which precludes the analysis of hCMV in animal models). Established animal models of CMV include cercopithecine herpesvirus 8 (CeHV8), also known as rhesus monkey cytomegalovirus; murid herpesvirus 1 (MuHV1), also known as murine or mouse cytomegalovirus (mCMV); murid herpesvirus 2 (MuHV2) or rat cytomegalovirus; and caviid herpesvirus 2 (CavHV2) or guinea-pig cytomegalovirus. Although all of these models have specific advantages for the study of different aspects of CMV disease, research on mCMV is most advanced with regard to the principles that govern the immune surveillance of CMVs. Collectively, these studies have indicated a central, although not exclusive, role for $\mathrm{CD} 8^{+} \mathrm{T}$ cells ${ }^{2}$. Therefore, this review focuses on the paradigmatic value of $\mathrm{mCMV}$ for our understanding of CMV disease and, in particular, disease prevention by antiviral $\mathrm{CD}^{+} \mathrm{T}$ cells.

Under the selective pressure that is exerted by the effector functions of innate and adaptive immunity, viruses have developed many defence strategies. Viral immune-evasion mechanisms have attracted great interest in the past few years and are the topic of several recent review articles ${ }^{3-5}$. CMVs have proved to be particularly inventive in subverting immune control at different levels of the immune response: they paralyse the antigen-presenting function of dendritic cells (DCs) during the priming of a response $e^{6-8}$, interfere with the presentation of antigenic peptides to $\mathrm{CD} 4^{+}$and $\mathrm{CD} 8^{+}$ $\mathrm{T}_{\text {cells }}{ }^{9-13}$ and can inhibit the effector function of natural killer (NK) cells by the inhibition of activating NK-cell receptors or by the activation of inhibitory NK-cell receptors ${ }^{14,15}$. In addition, CMVs manipulate leukocyte behaviour to their benefit by encoding homologues or analogues of cytokines, chemokines and cell-surface receptors that are involved in the immune response (for an overview, see REF. 16).

In this article, I do not intend to review the reviews, but rather, I wish to discuss the crucial, but sometimes somewhat neglected, question of how we manage to survive hCMV infection in the face of all of these viral immune-evasion mechanisms. 


\section{Box 1 | Cytomegalic inclusion disease}

The photograph (part a; courtesy of G. Jahn, Institute of Medical Virology, Tuebingen, Germany) shows a case of cytomegalic inclusion disease (CID), reported in 1988, from the Children's Hospital at Bayreuth, Germany ${ }^{110}$. CID is caused by congenital infection of the embryo or fetus with human cytomegalovirus (hCMV) by intrauterine transmission, which can occur, in particular, in the absence of maternal antibodies during primary infection of the mother or after her re-infection with a different virus strain ${ }^{111}$. Petechial (spot-like) haemorrhages in the skin and hepatosplenomegaly are indicative of CID. Frequent manifestations of CID include pneumonia, hepatitis with jaundice, retinitis, enteritis-colitis and microcephaly. In milder cases of CID, survivors often suffer from life-long neurological sequelae, such as mental retardation, deafness and blindness ${ }^{17}$. Organ disease results from cytopathogenic infection of tissue cells. The name CID reflects two pathognomonic cytopathological signs of CMV infection — namely, enlargement of the infected cells (cytomegaly) and the formation of an intranuclear inclusion body that is the site of viral DNA packaging into nucleocapsids (see figure, part b; in situ viral DNA hybridization in a liver section, see REF. 148 for details). For early pathologists, these cytomorphological changes were reminiscent of owl's eyes. Cytomegalic 'owl's eye' cells in the parotid gland and in kidney tubules of stillborns with Lues (syphilis)-like clinical symptoms were described in morphological detail in 1904 by Ribbert and by Jesionek and Kiolemenoglou. Originally, the cytomegalic cells were mistaken for protozoan-like stages and were associated with Lues. The viral aetiology of CID was proposed first in 1925 by von Glahn and Pappenheimer, but it took a further three decades until Smith, Weller and Rowe independently isolated the causative agent of CID, hCMV (for a more detailed historical perspective, see chapter 1 in REF. 112).

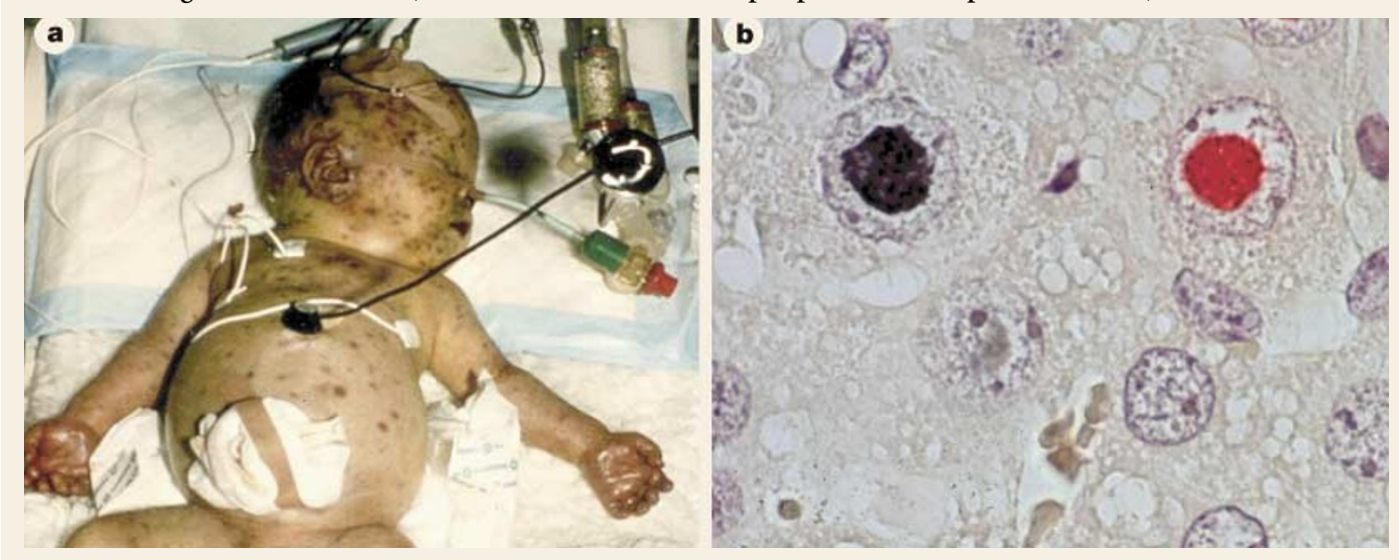

\section{A disease of the immunocompromised}

Human CMV is transmitted frequently from mother to child by breastfeeding, and through contaminated saliva and lacrimal fluid. Saliva and other bodily excretions are the main sources of virus for transmission from child to child, or child to care-giver's hand to child, in families and in child-care homes and centres. The 'mouthing' of hands and toys by infants is a recognized route of transmission. Susceptible mothers often acquire the virus from their own children. In adults, hCMV is also transmitted through sexual contact. In most developing areas of the world, the prevalence of infection reaches $100 \%$ in the adult population, whereas in developed countries, with a high proportion of one-child families and childcare within the family, the prevalence drops to around $50 \%$. Infection with hCMV is not usually a problem, because postnatal infection of children is harmless and primary infection of adults is associated with a mild mononucleosis that mostly goes unnoticed. So, why is hCMV important at all? The answer is that severe disease can develop in immunologically immature children for example, after congenital infection or after infection of premature infants (BOX 1). The life-long neurological sequelae that result from congenital hCMV infection are the main argument for considering an hCMV vaccine (BOX 2). Manifestations of CMV disease - in particular, chorioretinitis - are important complications of AIDS. In addition, interstitial pneumonia, gastrointestinal disease, hepatitis and graft failure are important health risks of hCMV infection in iatrogenically immunocompromised patients, such as recipients of bone-marrow transplants (BMT) or organ allografts (for an epidemiological and clinical perspective, see REF. 17).

What do these medical facts indicate to an immunologist or virologist who studies the immune-evasion mechanisms of CMVs? It seems that, whatever countermeasures CMVs have evolved to avoid recognition by the immune system, they surrender eventually to a superior immune surveillance that is effective in the face of all viral immune-evasion strategies. However, CMVs can avoid elimination in an individual host and they spread efficiently in the host population. After the resolution of productive infection by the immune effector functions, CMVs hide in host cells in a non-replicative state, known as LATENCY, and they reactivate sporadically to productive infection during periods of weakened immunity.

\section{Immune surveillance: importance of $\mathrm{CD8}^{+} \mathrm{T}$ cells}

Mouse models have been established in which primary infection of immunocompetent mice with mCMV does not cause CMV organ disease. Viral replication is inhibited rapidly in most organs, with the notable exception 


\section{Box 2 | Human cytomegalovirus: an under-rated health risk}

In comparison to other infectious diseases, there is little attention given to disease caused by human cytomegalovirus (hCMV) in the media and by public health service and science funding authorities. Recently, this has changed somewhat in the United States. On October 25-27, 2000, the National Vaccine Program Office convened a workshop in Atlanta on 'Cytomegalovirus Vaccine Development' to discuss the potential public-health strategies for hCMV vaccine administration on the basis of a study carried out by the Institute of Medicine (IOM, The National Academies, Washington, DC).

Out of candidate vaccines against 26 diseases that were included in that study, an hCMV vaccine aimed at preventing cytomegalic inclusion disease (CID) was one of seven that were grouped in Level I (most favourable) on the basis of estimated costs per quality-adjusted life year (QALY) gained by a vaccine strategy. Level I includes potential vaccines that are predicted to not only save lives and prevent life-long disability, which is an ethical issue, but also to reduce the net cost of health care. On the basis of less-thanideal and ideal assumptions for vaccination coverage and vaccine efficacy, the IOM study committee estimated a gain of 18,000-70,000 QALYs and an annual saving to the health system of US $\$ 1.1$ billion-4.0 billion. These estimates for the Unites States can be extrapolated to developed countries that have comparable hCMV epidemiology. The current state of hCMV vaccine development has been reviewed recently by Britt ${ }^{113}$ and by Gonczol and Plotkin ${ }^{114}$.

Disease caused by hCMV infection in the United States

Congenital infection

Cases per annum: 40,000

Asymptomatic at birth: 36,000 (5,400 of whom had neurological sequelae; 0 deaths)

Symptomatic at birth: 4,000 (3,600 of whom had neurological sequelae; 400 deaths)

\section{Transplantation-associated hCMV}

Cases per annum: 2,800

Moderate disease: 1,200 (0 deaths)

Severe disease (mainly pneumonia and gastrointestinal disease): 1,600 (160 deaths)

These data have been adapted, with permission, from the contribution of R. S. Lawrence (chairman of the IOM committee) to the Atlanta workshop. For further details, see REF. 115.

\section{ANTIVIRAL}

CYTOIMMUNOTHERAPY

Prevention or treatment of viral

disease in a recipient by the

adoptive transfer of immune

cells, usually by intravenous

infusion of the cells. of the salivary glands. There, virus production persists for a prolonged period of time in a cell type that is specialized for secretion - the acinar glandular epithelial cell $^{18}$. The virus uses the physiological secretion pathway of this polarized cell to leave the body through the salivary duct for transmission from host to host. This scenario is markedly different in mice in which all components of cellular immunity have been destroyed by irradiation ${ }^{19}$. Under those conditions, the mice succumb to a high-level cytopathogenic infection of vital organs, including lungs, liver, adrenal glands, kidneys and gastrointestinal tract ${ }^{19,20}$. The disease manifestations in these mice - in particular, the interstitial pneumonia - resemble hCMV disease ${ }^{21,22}$.

Components of innate and adaptive immunity contribute to the control of primary mCMV infection. There is ample evidence of a pivotal role for NK cells in genetically determined natural resistance to $\mathrm{mCMV}$, in mice with genetically impaired adaptive immunity and, in general, during the early stages of infection ${ }^{23-27}$. Although NK cells provide the first line of defence against acute infection, adaptive immunity is required at later stages for sustained immune surveillance. This was highlighted by an experiment carried out by Welsh et al. ${ }^{28}$. In contrast to CB17 wild-type mice, mutants with severe combined immunodeficiency (SCID) - which are defective in the rearrangement of antigen-specific receptors and, therefore, depend on innate immunity - failed to control mCMV infection in the long term and succumbed to CMV disease. The long-term protective component of adaptive cellular immunity was identified as being $\mathrm{CD} 8^{+}$ $\mathrm{T}$ cells ${ }^{19,29}$. Specifically, when isolated from a draining lymph node during acute infection ${ }^{19}$ or from the spleen during latent infection ${ }^{30}$, effector and memory $\mathrm{CD}^{+}$ $T$ cells protected against lethal $\mathrm{mCMV}$ disease after adoptive cell transfer into immunocompromised, infected recipients, whereas the depletion of $\mathrm{CD}^{+} \mathrm{T}$ cells from the transferred lymphocyte population markedly reduced its antiviral activity. Consistent with this result, the control of mCMV was mediated by the remaining $\mathrm{CD}^{+} \mathrm{T}$-cell population in mice that were long-term depleted of $\mathrm{CD} 4^{+} \mathrm{T}$ cells before infection and, hence, were deficient in the production of antiviral antibodies ${ }^{18}$. It has been shown that antiviral antibodies are not involved crucially in the control of primary mCMV infection, but that they limit the viral dissemination of a recurrent infection and protect against secondary infection ${ }^{31}$.

A notable lesson was learnt from the study of primary mCMV infection in mice that were long-term depleted of $\mathrm{CD}^{+} \mathrm{T}$ cells before infection ${ }^{32}$ or that lacked expression of functional MHC class I molecules genetically ${ }^{33}$. Instead of developing disease, these mice controlled the infection by a mechanism that involved $\mathrm{CD}^{+}$ $\mathrm{T}$ cells. So, in these particular experimental settings, $\mathrm{CD}^{+} \mathrm{T}$ cells were dispensable and $\mathrm{CD} 4^{+} \mathrm{T}$ cells took up a new role, which they did not have in the presence of $\mathrm{CD}^{+} \mathrm{T}$ cells. Therefore, it was tempting to conclude that 'plasticity' of the immune system always ensures control of mCMV, regardless of which T-cell subset is present.

This conclusion was shown to be incorrect by a mouse model of CMV-associated interstitial pneumonia after BMT, which is a model of a clinically relevant manifestation of hCMV disease in BMT patients. $\mathrm{CD} 8^{+}$ T-cell populations generated endogenously during haematopoietic reconstitution in the presence of mCMV were found to be recruited to infected lungs, to increase massively in size and to form focal infiltrates around clusters of infected lung cells, thereby confining and eventually resolving productive infection ${ }^{21,34}$. For the 'proof of principle', the protective antiviral role of the infiltrating $\mathrm{CD} 8^{+} \mathrm{T}$ cells was shown by two complementary approaches. First, in vivo depletion of $\mathrm{CD}^{+}$ T cells by anti-CD8 antibodies prevented focal infiltration of the infected lungs and led to lethal organ disease, including disseminated pneumonia ${ }^{20,21}$. Second, pulmonary $\mathrm{CD}^{+} \mathrm{T}$ cells isolated from the infected lungs prevented virus replication and disease in immunocompromised recipients after cell transfer ${ }^{21,35}$. So, in an experimental BMT setting, the efficient reconstitution of antiviral $\mathrm{CD}^{+} \mathrm{T}$ cells was essential for the resolution of organ infection. Clinical data from BMT patients confirm a crucial role for $\mathrm{CD}^{+} \mathrm{T}$ cells in the control of hCMV. Recovery from hCMV infection is correlated with the reconstitution of $\mathrm{CD}^{+} \mathrm{T}$ cells ${ }^{36}$. Accordingly, in clinical trials of ANTIVIRAL CYTOIMMUNOTHERAPY, the transfer of antiviral $\mathrm{CD}^{+} \mathrm{T}$-cell lines reduced the incidence of post-transplantation CMV disease ${ }^{37}$. 


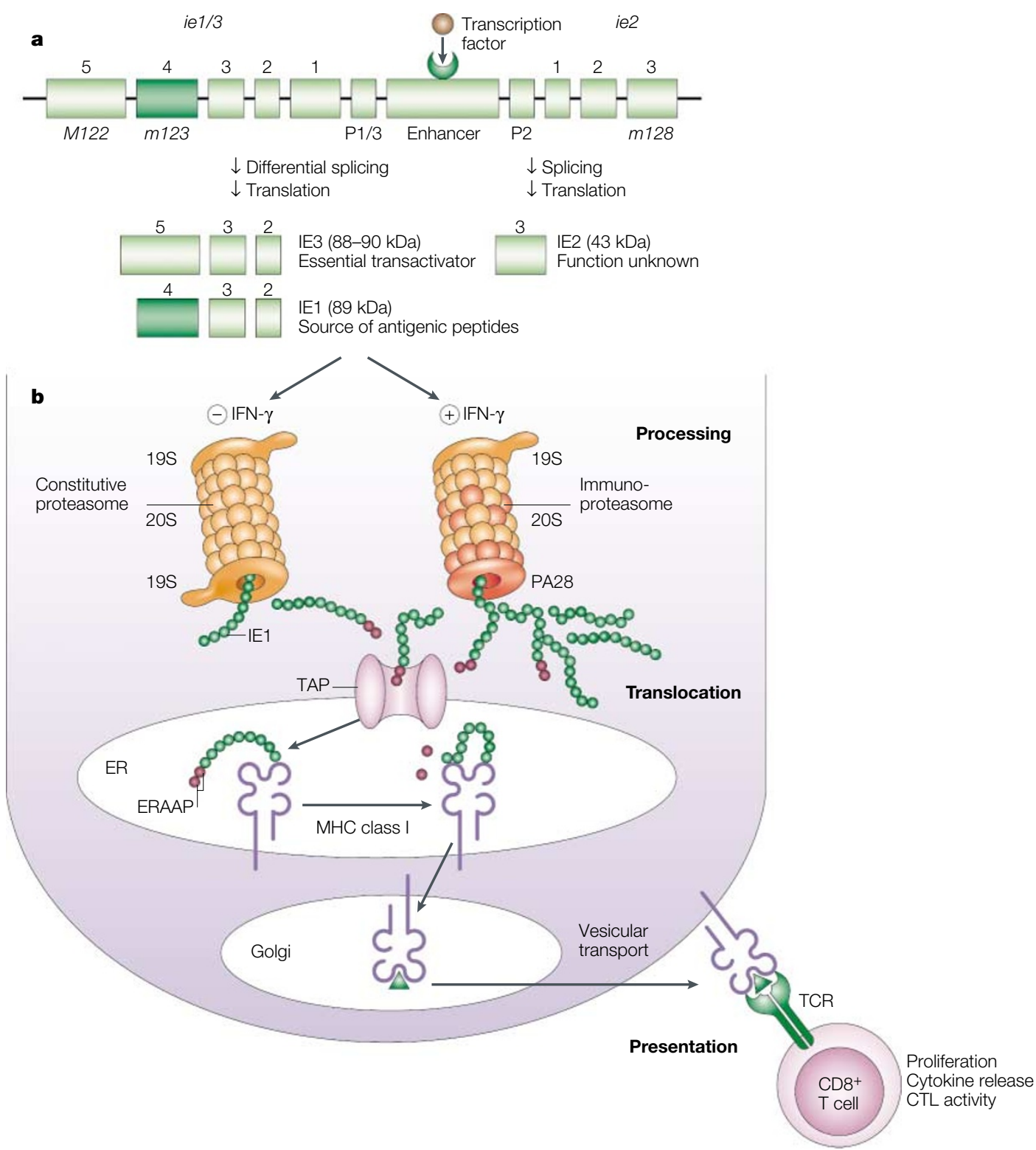

Figure 1 | Molecular biology of the murine cytomegalovirus IE1 peptide. a | Genomic organization of the major immediateearly (MIE) region of murine cytomegalovirus ( $\mathrm{mCMV}$ ). MIE genes are the immediate-early (IE) genes, which are expressed most abundantly in the IE phase. A strong cis-acting regulatory element, the MIE enhancer, which responds to the binding of transcription factors, is flanked by the transcription unit ie1/3 (open reading frames $M 122$ and $m 123$ ) and gene ie2 (open reading frame $m 128$ ), driven by the specific promoters P1/3 and P2, respectively ${ }^{116-119}$. Differential splicing of ie $1 / 3$ results in two proteins, IE1 (encoded by exons 2, 3 and 4) and IE3 (encoded by exons 2, 3 and 5). Protein IE2 is encoded by exon 3 of the gene ie2. IE1 (a phosphoprotein of $89 \mathrm{kDa}$ ) transactivates cellular genes that are involved in nucleotide metabolism to allow virus replication in resting cells ${ }^{120}$. The role of IE2 is unknown. It is dispensable for virus replication in cell culture and in vivo ${ }^{121}$. IE3 is an essential transactivator of viral early gene expression ${ }^{122} . \mathbf{b} \mid$ Processing and presentation of the IE1 peptide during the IE phase. Using the BALB/C (haplotype H-2 ${ }^{d}$ )derived IE-phase-specific cytotoxic T lymphocyte (CTL) clone IE1, an antigenic nonapeptide with the amino-acid sequence YPHFMPTNL and presented by the MHC class I molecule H-2 ${ }^{d}$ was identified for positions 168-176 (encoded by exon 4) of the IE1 protein ${ }^{45}$. In the $20 S$ core proteasome, cleavage of the IE1 protein generates the IE1 nonapeptide and the amino-terminally elongated precursor DMYPHFMPTNL ${ }^{123}$. This process is accelerated by the interferon- $\gamma($ IFN- $\gamma)$-inducible 11 S proteasome modulator complex PA28 $\alpha-\beta$, which substitutes for one of the two $19 S$ regulator complexes of the $26 S$ proteasome. Owing to the adverse effect of proline in position 2 of the 9-mer, only the 11-mer precursor is translocated to the lumen of the endoplasmic reticulum (ER) by transporter for antigen processing (TAP) ${ }^{123}$. It is proposed that the final 9 -mer is generated in the ER from the 11-mer precursor by amino-terminal peptide trimming exerted by the ER aminopeptidase associated with antigen processing $(E R A A P)^{124,125}$. The 9-mer binds to $\mathrm{H}-2 \mathrm{~L}^{d}$ to form a fully folded peptide- $\mathrm{H}-2 \mathrm{~L}^{\mathrm{d}}$ complex. In accordance with the $\mathrm{H}-2 \mathrm{~L}^{\mathrm{d}}$ binding motif $\mathrm{X}-\mathrm{P} / \mathrm{S}-\mathrm{X}_{6}-\mathrm{F} / \mathrm{L} / \mathrm{M}^{126}$, proline in position 2 and leucine in the carboxy-terminal position 9 were identified as the $\mathrm{MHC}$ anchor residues of the 9-mer ${ }^{127}$. Through the Golgi apparatus and by vesicular transport, the peptide-H-2 $\mathrm{L}^{\mathrm{d}}$ complex reaches the cell surface. There, it stimulates CTLs that have a complementary T-cell receptor (TCR) to proliferate, secrete cytokines and lyse the infected target cell. Adapted, with permission, from Nature Reviews Molecular Cell Biology (Kloetzel, P.-M. Ubiquitin and proteasomes: antigen processing by the proteasome. 2, 179-188) @ (2001) Macmillan Magazines Ltd. 
The importance of $\mathrm{CD}^{+} \mathrm{T}$ cells for the control of infection with mCMV, as well as hCMV, raises the question of which viral proteins elicit the protective antiviral immune response. This is an important issue for vaccine development.

\section{The IE1 antigen}

Cytomegaloviruses have a high protein-coding capacity, predicted to be approximately 165 and 170 open reading frames (ORFs) for $\mathrm{hCMV}^{38}$ and $\mathrm{mCMV}^{39}$, respectively (for a review of the molecular biology of CMVs, see REF. 40). The large number of homologous ORFs indicates that the two viruses are closely related, but gene families do exist that are unique to each virus. Gene expression in members of the herpesvirus family is coordinately regulated, which led to the definition of three temporal gene classes, known as immediateearly (IE), early (E) and late (L) genes ${ }^{41}$. IE genes are the first viral genes to be transcribed in the infected cell by cellular RNA polymerase II, whereas transition to the $\mathrm{E}$ phase depends on the transactivation of $\mathrm{E}$-gene promoters by an IE protein. The $\mathrm{L}$ phase is defined by the onset of viral DNA synthesis.

Early work in the mouse model showed that mCMV-infected fetal fibroblasts are recognized by polyclonal $\mathrm{CD}^{+}$cytotoxic $\mathrm{T}$ lymphocytes (CTLs) in all three phases ${ }^{42}$. Interest was then focused on the observed high frequency of CTLs specific for infected cells that are arrested at the IE phase by metabolic inhibitors ${ }^{43}$, because, at that time, it was not known how regulatory intranuclear proteins could be recognized by CTLs at the cell surface. In the following years, work by Koszinowski's group led to the molecular identification of an immediate-early protein 1 (IE1)-derived peptide of $\mathrm{mCMV}^{44,45}$, the first antigenic peptide to be described for CMVs (FIG. 1).

A selective pressure exerted on mCMV by IE1-specific CTLs was indicated by the natural variation of the IE1 peptide sequence between $\mathrm{mCMV}$ isolates from feral mice $^{46}$. The role of IE1-specific CTLs in protection against CMV disease was shown directly in the mouse model by several approaches (in chronological order): by immunization with a vaccinia-virus recombinant expressing ORF $m 123$, which encodes the IE1 protein (REE. 47); by immunization with a vaccina-virus recombinant expressing the IE1 nonapeptide sequence in hepatitis B virus core antigen as an unrelated carrier protein $^{48}$; by immunization with synthetic IE1 peptide in adjuvant ${ }^{49}$; by genetic immunization with an expression plasmid containing ORF $m 123$ (REF. 50); by PRE-EMPTIVE CYTOIMMUNOTHERAPY with IE1-peptidespecific CTL lines ${ }^{51,52}$ (FIG. 2a); and by pre-emptive cytoimmunotherapy with ex vivo IE1-peptide-specific $\mathrm{CD}^{+}$memory $\mathrm{T}$ cells sorted from the spleen of latently infected mice using IE1-peptide-loaded immunoglobulin-H-2 $\mathrm{L}^{\mathrm{d}}$ hybrid molecules (M.-F. Pahl-Seibert and M.J.R., unpublished observations) (FIG. 2b).

The immunological relevance of the corresponding IE1 protein of hCMV (ppUL123 or pp72 kDa) has been debated for a long time. By contrast, ppUL83 (pp65 kDa) was regarded as the only candidate for a T-cell vaccine against hCMV, because a large number of ppUL83-specific $\mathrm{CD} 8^{+} \mathrm{T}$ cells can be detected in the peripheral blood of hCMV-seropositive individuals ${ }^{53,54}$. In addition, data indicate that there is a selective inhibition of IE1 antigen processing by the phosphorylation of IE1, which is carried out by a ppUL83-associated kinase activity ${ }^{55}$. However, more than a decade after the first report of IE1-specific human CTLs ${ }^{56}$, there is now a renaissance of interest in hCMV IE1 as an antigen ${ }^{57,58}$. As shown by Kern et al. ${ }^{57}$, the relative prevalence of IE1and ppUL83-specific $\mathrm{CD}^{+} \mathrm{T}$ cells varies between individuals; the IE1-specific response dominates in some individuals, whereas the ppUL83-specific response dominates in others. Khan et al. ${ }^{59}$ showed recently that there are comparable frequencies of $\mathrm{CD} 8^{+} \mathrm{T}$ cells specific for an IE1 peptide and a ppUL83 peptide, which are both presented by HLA-A2.

\section{Immunoevasins}

Under the selective evolutionary pressure exerted by $\mathrm{CD}^{+} \mathrm{T}$ cells, $\mathrm{mCMV}$ and hCMV have acquired sets of genes, the only known function of which is to encode glycoproteins that interfere with antigen presentation by the classical MHC class I pathway and that have no apparent sequence homology or functional analogy to known cellular proteins (TABLE 1). In accordance with a recent definition used by the group of Koszinowski, who is a pioneer of this field ${ }^{60}$, the term 'immunoevasin' is used here for this specific class of viral molecules. However, it should be noted that many other virus-encoded molecules - including MHC class I homologues, or homologues of cytokines and chemokines and their receptors might contribute to the viral subversion of various immune functions at different levels of the immune response. The fact that immunoevasin genes of $\mathrm{mCMV}$ and hCMV are unique to either virus and do not have any sequence homology indicates that there is specific adaptation to the respective host. The related function of the proteins represents biological convergence, which indicates that analogous principles of immune surveillance of CMVs operate in mice and humans.

Although the goal is the same, the molecular mechanisms by which the two viruses manipulate the expression of MHC class I molecules are distinct in the details (FIG. 3). A hallmark of the $\mathrm{E}$ and $\mathrm{L}$ phases of mCMV infection is the accumulation of peptide-loaded MHC class I complexes in a cis-Golgi compartment, which is induced by the ORFm152-encoded protein $\mathrm{m} 152$ (gp37/40) ${ }^{61-64}$ (FIG. 3A). A similar intracellular retention of MHC class I complexes in infected fibroblasts has been observed in early work on $\mathrm{hCMV}^{65}$, and it is now ascribed to the action of gpUS3 (REFS 66,67). A feature that is unique to hCMV infection is the proteasomal degradation of MHC class I $\alpha$-chains ${ }^{68}$, a process that involves retrograde translocation of the $\alpha$-chains from the endoplasmic reticulum to the cytosol mediated by the viral E-gene products gpUS2 and/or gpUS11 (REFS 69-71) (FIG. 3B). 


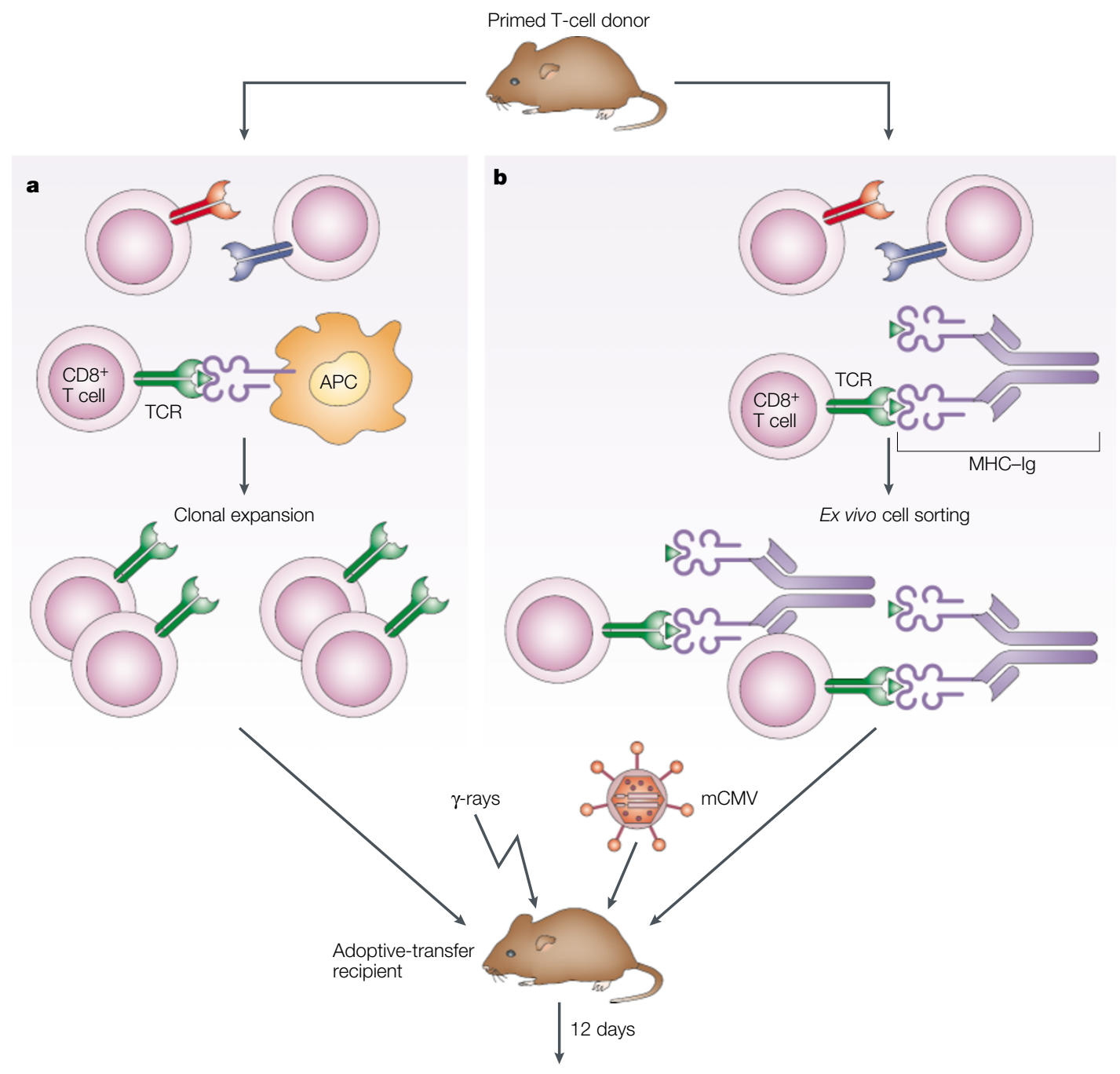

Transfer a

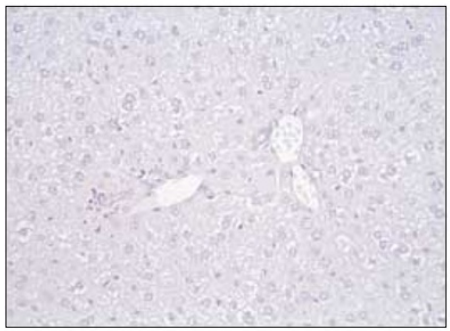

Virus clearance
No transfer

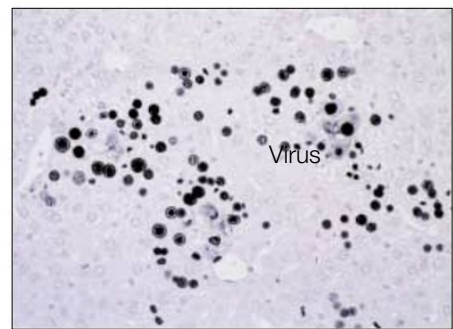

CMV hepatitis
Transfer b

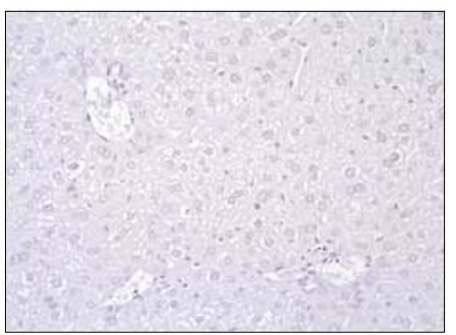

Virus clearance

Figure 2 | Testing for antiviral activity of CD8+ $\mathbf{T}$ cells in vivo. Immune cells are isolated from lymphoid organs or tissue infiltrates of mice during acute or latent murine cytomegalovirus (mCMV) infection. a | Generation of peptide-specific cytotoxic T lymphocyte (CTL) lines. CD8 ${ }^{+} T$ cells present in the lymphocyte population and expressing a specific T-cell receptor (TCR) are stimulated for proliferation in cell culture by antigen-presenting cells (APCs) that present the cognate antigenic peptide (added to the culture as a synthetic peptide at a defined molar concentration). After several rounds of stimulation, a CTL line specific for the stimulating peptide has been selected. $\mathbf{b} \mid$ Ex vivo isolation of peptide-specific memory or effector cells. CD8 ${ }^{+} \mathrm{T}$ cells that express a specific TCR are labelled with an $\mathrm{MHC}$ class I molecule-immunoglobulin (MHC-Ig) fusion protein that presents the cognate peptide on its $\mathrm{MHC}$ portion. This labelling technique does not destroy cell function. The peptide-specific cells are isolated by cytofluorometric cell sorting. After selection of peptide-specific CD8 ${ }^{+} T$ cells, their antiviral function is tested by intravenous cell transfer (pre-emptive cytoimmunotherapy) into immunocompromised and infected syngeneic recipient mice. The antiviral effect can be measured as survival rate, reduced viral infectivity load in organs or reduced number of infected tissue cells as determined by in situ hybridization (for viral DNA or messenger RNA) or by immunohistology (for viral protein). As an example, the immunohistological detection of mCMV IE1 protein (black staining) 52 in the nuclei of infected hepatocytes during mCMV hepatitis after no cell transfer is compared with the transfer of cells from parts $\mathbf{a}$ and $\mathbf{b}$. Other target organs of mCMV, such as spleen, lungs and adrenal glands, are analysed accordingly. Histological data by courtesy of J. Podlech, Institute for Virology, Mainz, Germany. 
REVIE W S

\begin{tabular}{|c|c|c|c|c|}
\hline ORF* $^{\star}$ & Protein & Phase & Proposed mode of action & References \\
\hline \multicolumn{5}{|c|}{ Murine cytomegalovirus } \\
\hline m04 & gp34 & $E / L$ & Binds to and escorts MHC class I molecules to the cell surface & 77,78 \\
\hline m06 & gp48 & $E$ & 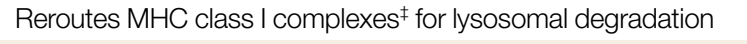 & 128 \\
\hline$m 152$ & gp37/40 & $E$ & Triggers retention of $\mathrm{MHC}$ class I complexes in the ERGIC & $61-64$ \\
\hline \multicolumn{5}{|c|}{ Human cytomegalovirus } \\
\hline US2 & gp24 & $E$ & Reroutes MHC class I $\alpha$-chains for proteasomal degradation & 69,132 \\
\hline US3 & gp23 & $\mathrm{IE}$ & Retains MHC class I complexes in the ER & 66,67 \\
\hline US6 & gp21 & $\mathrm{E} / \mathrm{L}$ & Blocks TAP-mediated translocation of peptides into the ER & $129-131$ \\
\hline US11 & gp33 & $\mathrm{E}$ & Reroutes MHC class I $\alpha$-chains for proteasomal degradation & $70,71,76$ \\
\hline
\end{tabular}

In mCMV infection, presentation of the immunodominant peptides IE1 (amino acids 168-176) and M45 (amino acids 985-993) by the MHC class I molecules $\mathrm{H}-2 \mathrm{~L}^{\mathrm{d}}$ and $\mathrm{H}-2 \mathrm{D}^{\mathrm{b}}$, respectively, is prevented during the $E$ phase in infected fibroblasts ${ }^{72,73}$. This immune-evasion phenotype is abrogated by deletion of the $m 152$ gene in the recombinant virus $\Delta m 152-\mathrm{mCMV}^{73,74}$; therefore, it seems that the two remaining immunoevasins, $\mathrm{m} 04$ (gp34) and m06 (gp48), are not involved crucially. A biologically important role for immunoevasin $\mathrm{m} 152$ is indicated by the $\mathrm{CD}^{+} \mathrm{T}$-cell-mediated in vivo attenuation of the mutant virus $\Delta m 152-\mathrm{mCMV}^{74}$. Of particular interest is the recent finding that $\mathrm{m} 152$ counters adaptive and innate immune control simultaneously in the mCMV-susceptible mouse strain BALB/c. It triggers intracellular retention of MHC class I complexes to compromise control by $\mathrm{CD} 8^{+} \mathrm{T}$ cells, and it downmodulates cell-surface expression of the high-affinity ligand $\mathrm{H}-60$ for the activating NK-cell receptor NKG2D to compromise control by NK cells ${ }^{75}$. Immunoevasins gpUS3 and gpUS2 of hCMV counter both arms of the T-cell response simultaneously. In addition to effects on the MHC class I pathway (FIG. 3B), they also interfere with peptide presentation by the MHC class II pathway, by inducing the mislocalization and degradation of MHC class II molecules ${ }^{13}$.

The list of immunoevasins that operate by downmodulating the cell-surface expression of classical MHC class I molecules seems to be complete for mCMV and hCMV, because the expression of MHC class I molecules is not affected during infection with the deletion mutants $\Delta m 04+m 06+m 152-\mathrm{mCMV}^{60}$ and $\Delta U S 2-$ US11-hCMV ${ }^{76}$. Immunoevasin m04 of mCMV is an exception in that it does not operate by the downmodulation of MHC class I cell-surface expression ${ }^{60,77,78}$. Therefore, to be precise, the possible existence of unidentified immunoevasins with m04-like function has not been excluded for mCMV.

\section{Interplay between immunoevasins}

It is an important question why both mCMV and hCMV encode such a wide range of glycoproteins targeted at the MHC class I pathway of antigen processing and presentation. One reason for redundancy is to cope with MHC polymorphism. For example, the action of gpUS2 is allele and locus specific in that it binds to several products of the HLA-A locus, but not to HLAB7, -B27, -Cw4 or - $\mathrm{E}^{79}$. Unlike H-2K $\mathrm{K}^{\mathrm{d}}, \mathrm{H}-2 \mathrm{D}^{\mathrm{d}}, \mathrm{H}-2 \mathrm{~L}^{\mathrm{d}}$ and $\mathrm{H}-2 \mathrm{D}^{\mathrm{b}}$, cell-surface expression of the $\mathrm{H}-2 \mathrm{~K}^{\mathrm{b}}$ allelic product of the mouse MHC is downregulated poorly by the concerted action of the three immunoevasins of $\mathrm{mCMV}^{60}$. Cell-type-specific adaptation is a second reason for redundancy. As an example, gpUS11 is more effective than gpUS2 at mediating the degradation of MHC class I molecules selectively in primary human $\mathrm{DCs}^{80}$. The third reason is cooperation. Complexes that are retained in the endoplasmic reticulum by gpUS3 during the IE phase are removed by gpUS2- and/or gpUS11-mediated degradation during the $\mathrm{E}$ phase ${ }^{67}$. A recent example for $\mathrm{mCMV}$ has shown that $\mathrm{m} 152$ is sufficient to prevent $\mathrm{H}-2 \mathrm{D}^{\mathrm{b}}$-restricted peptide recognition, whereas evasion of $\mathrm{H}-2 \mathrm{~K}^{\mathrm{b}}$-restricted peptide recognition requires the help of m04 (REF. 81).

Our current view, as shown in FIG. 3 , is based mainly on the isolated expression of immunoevasins in transfection systems, which does not indicate any possible interference between immunoevasins in an infected cell. In mCMV infection, the three known immunoevasins are expressed in the $\mathrm{E}$ phase and compete for the same substrate, namely MHC class I molecules. Koszinowski and colleagues have started a systematic analysis of the interplay between immunoevasins in cells infected with wild-type mCMV or with immunoevasin gene-deletion mutants of mCMV that express the three immunoevasins in all seven possible combinations. The most notable new information provided by these mutants so far is that m04 abrogates m152-induced downmodulation of MHC class I cell-surface expression in mutant $\Delta m 06-\mathrm{mCMV}$, whereas it does not affect the m06mediated downmodulation of MHC class I molecules in mutant $\Delta m 152-\mathrm{mCMV}^{60}$. A probable explanation is that m06 binds stably to MHC class I molecules and re-routes them for lysosomal degradation before $\mathrm{m} 04$ gets a chance to interact, whereas $\mathrm{m} 152$ binds transiently to MHC class I molecules, which gives $\mathrm{m} 04$ a chance to replace $\mathrm{m} 152$ and to escort the MHC molecules to the cell 
surface. It is predicted that the immunoevasin mutants of Wagner et al.$^{60}$ will soon change our ideas about the molecular action of immunoevasins.

\section{Antigens}

The models proposed in FIG. 3 indicate that peptide presentation is prevented during the $\mathrm{E}$ and $\mathrm{L}$ phases of
mCMV infection and during all three phases of hCMV infection. Clearly, this cannot be the whole story. As shown by earlier work in the mouse model, polyclonal CTLs recognize mCMV-infected cells in all three temporal phases of the viral replication cycle ${ }^{42}$. Notably, CTLs isolated from pulmonary infiltrates during $\mathrm{mCMV}$ pneumonia and tested directly for cytolytic activity lysed
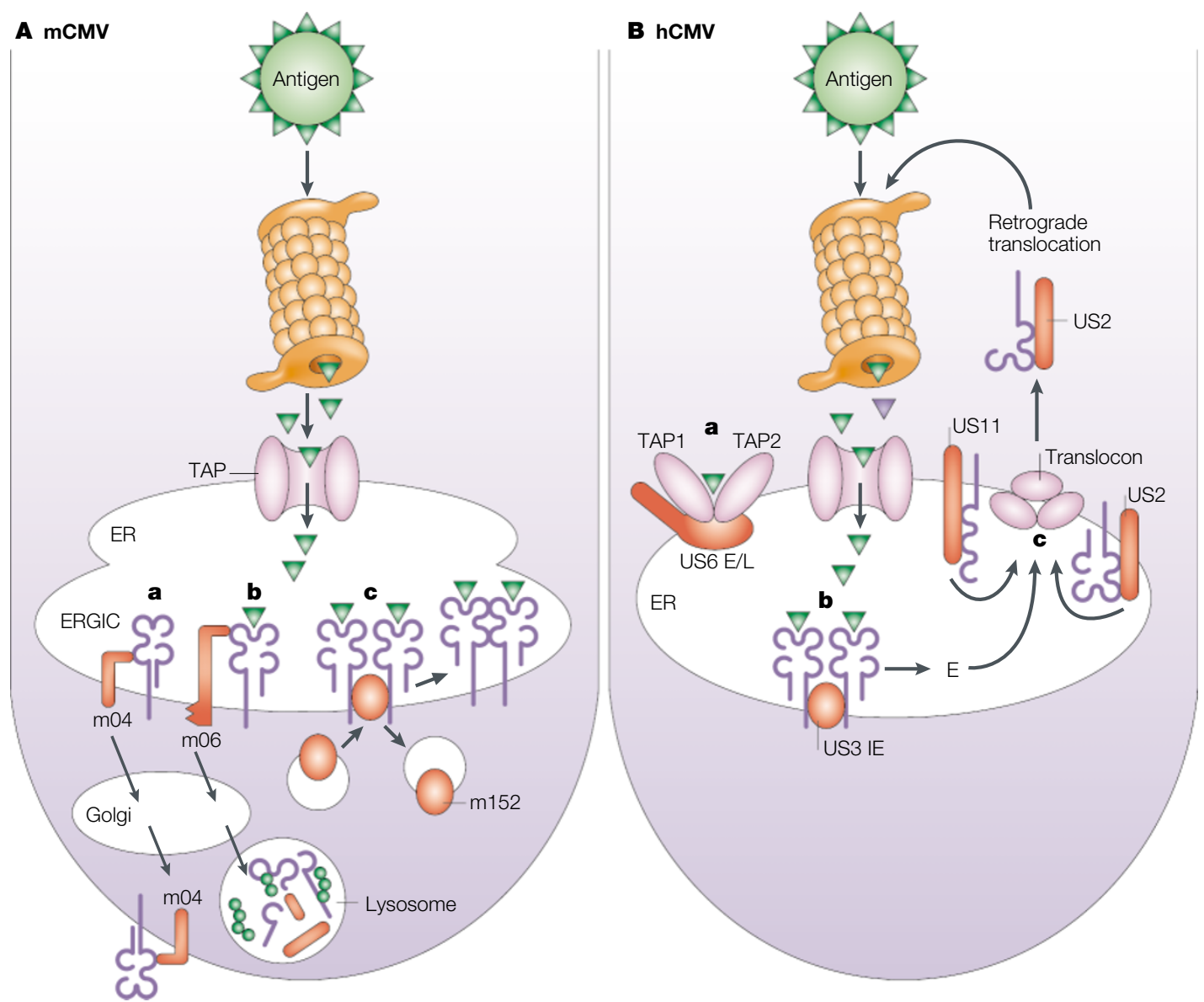

Figure 3 | Models proposed for the action of immunoevasins. A | Immunoevasins of murine cytomegalovirus (mCMV). a $\mathrm{m0} 4$ binds to $\mathrm{MHC}$ class I molecules in the endoplasmic reticulum (ER) and escorts them to the cell surface. By passing through the Golgi apparatus, it acquires two endoglycosidase-H-resistant oligosaccharide chains. MHC class I molecules and m04 can be co-precipitated from the cell surface. The complex does not seem to be recognized by CD8 $+\mathrm{T}$ cells. It is unclear whether the complexed $\mathrm{MHC}$ molecules do not present peptide or whether the bound m04 prevents recognition. m04-mediated surface display of $\mathrm{MHC}$ class I molecules might silence natural killer (NK) cells ${ }^{77,78}$. b $\mid$ m06 binds through a lumenal domain to peptide-loaded MHC class I molecules in the ER and reroutes the resulting complex to a late endosomal/lysosomal compartment for degradation. A di-leucine motif in the cytoplasmic tail of $\mathrm{m06}$ is required for this function ${ }^{128}$. c $\mid \mathrm{m} 152$ triggers the retention and accumulation of peptide-loaded MHC class I molecules in the ER Golgi intermediate compartment (ERGIC). It does not form stable complexes with class I molecules. It seems to associate transiently and induce a modification of MHC class I complexes that might prevent their interaction with cargo receptors ${ }^{61-64}$. B | Immunoevasins of human cytomegalovirus (hCMV). a | US6 blocks peptide translocation through the transporter for antigen processing (TAP) by interaction with the lumenal surfaces of both subunits of the TAP1-TAP2 heterodimer in the transient peptide-loading complex - which consists of TAP, the MHC class I complex and ER-resident chaperones. It does not interfere with peptide binding to the cytosolic surface of TAP. It is proposed that a conformational change inhibits ATP-dependent peptide translocation by the prevention of ATP binding to the cytosolic nucleotide-binding domain of $\mathrm{TAP}^{129-131}$. b | US3 is an immediate-early (IE) protein that causes retention of peptide-loaded MHC class I molecules in the ER. Its lumenal domain is sufficient for retention, whereas binding to class I molecules requires, in addition, the transmembrane segment. US3-bound complexes are degraded in the early (E) phase by US2- and/or US11-mediated mechanisms ${ }^{66,67}$. c $\mid$ US2 and US11 both induce rapid proteasomal degradation of $\mathrm{MHC}$ class I $\alpha$-chains by mediating retrograde translocation from the ER to the cytosol. As has been shown for US2, retrograde translocation involves the 'translocon', a pore complex that is formed by the Sec61 $\alpha-\beta-\gamma$ heterotrimer and translocating chain-associating membrane protein (TRAM) ${ }^{69}$. US2 and US11 can bind to unfolded $\alpha$-chains, as well as to the folded MHC class I molecules. The crystal structure of US2 in complex with HLA-A2 reveals binding of US2 to the junction between the class I $\alpha 3$ domain and the peptide-binding region ${ }^{132}$. Unlike US11, which remains in the ER membrane, US2 seems to be co-dislocated and to escort the MHC class I $\alpha$-chain to the cytosol ${ }^{71}$. L, late phase. 


\begin{tabular}{|c|c|c|c|c|c|}
\hline ORF* & Protein & Phase & Antigenic peptide ${ }^{\ddagger}$ & $\begin{array}{l}\text { MHC class I } \\
\text { molecule }\end{array}$ & References \\
\hline \multicolumn{6}{|c|}{ Murine cytomegalovirus } \\
\hline m04 & gp34 & $E / L$ & 243-YGPSLYRRF-251 & $H-2 D^{d}$ & 51 \\
\hline$m 18$ & & E & 346-SGPSRGRII-354 & $H-2 D^{d}$ & 133 \\
\hline M45 & & E & $\begin{array}{l}\text { 985-HGIRNASFI-993 } \\
\text { 507-VGPALGRGL-515 }\end{array}$ & $\begin{array}{l}H-2 D^{b} \\
H-2 D^{d}\end{array}$ & 73 \\
\hline M83 & pp105 & $\mathrm{E} / \mathrm{L}$ & 761-YPSKEPFNF-769 & $\mathrm{H}-2 \mathrm{~L}^{\mathrm{d}}$ & 84 \\
\hline M84 & p65 & E & 297-AYAGLFTPL-305 & $\mathrm{H}-2 \mathrm{~K}^{\mathrm{d}}$ & 134 \\
\hline$m 123$ & $\begin{array}{l}\text { IE1, } \\
\text { pp89 }\end{array}$ & $\mathrm{IE}$ & 168-YPHFMPTNL-176 & $\mathrm{H}-2 \mathrm{~L}^{\mathrm{d}}$ & 45 \\
\hline$m 164$ & & E & 257-AGPPRYSRI-265 & $H-2 D^{d}$ & 52 \\
\hline \multicolumn{6}{|c|}{ Human cytomegalovirus } \\
\hline UL32 & pp150 & E/L & $\begin{array}{l}\text { 945-TTVYPPSSTAK-955 } \\
\text { 792-QTVTSTPVQGR-802 }\end{array}$ & $\begin{array}{l}\text { HLA-A3 } \\
\text { HLA-A68 }\end{array}$ & $\begin{array}{l}82 \\
82\end{array}$ \\
\hline UL55 & gB & $E / L$ & 618-(F)IAGNSAYEYV-628 & HLA-A2 & 135,136 \\
\hline UL83 & pp65 & $\begin{array}{l}\text { viral } \\
\text { entry } \\
\text { and } \\
E / L\end{array}$ & $\begin{array}{l}\text { 363-YSEHPTFTSQY-373 } \\
\text { 14-VLGPISGHV-22 } \\
\text { 120-MLNIPSINV-128 } \\
\text { 495-NLVPMVATV-503 } \\
\text { 16-GPISGHVLK-24 } \\
\text { 113-VYALPLKML-121 } \\
\text { 341-QYDPVAALF-349 } \\
\text { 369-FTSQYRIQGKL-379 } \\
\text { 186-FVFPTKDVALR-196 } \\
\text { 265-RPHERNGFIV-274 } \\
\text { 417-(TPRVTGGGAM-426 } \\
\text { 123-IPSINVHHY-131 } \\
\text { 187-VFPTKDVAL-195 } \\
\text { 367-PTFTSQYRIQGKL-379 } \\
\text { 512-EFFWDANDIY-521 }\end{array}$ & $\begin{array}{l}\text { HLA-A1 } \\
\text { HLA-A2 } \\
\text { HLA-A2 } \\
\text { HLA-A2 } \\
\text { HLA-A11 } \\
\text { HLA-A24 } \\
\text { HLA-A24 } \\
\text { HLA-A24 } \\
\text { HLA-A68 } \\
\text { HLA-B7 } \\
\text { HLA-B7 } \\
\text { HLA-B35 } \\
\text { HLA-B35 } \\
\text { HLA-B38 } \\
\text { HLA-B44 }\end{array}$ & $\begin{array}{r}82,137 \\
138 \\
138 \\
53,139 \\
82,137 \\
140 \\
141 \\
82 \\
82 \\
142 \\
53,142,143 \\
144 \\
53,145 \\
82 \\
53,142\end{array}$ \\
\hline UL123 & $\mathrm{IE} 1, \mathrm{pp} 72$ & $\mathrm{IE}$ & $\begin{array}{l}\text { 315-Y(V/I)LEETSVM-323" } \\
\text { 316-VLEETSVML-324ף } \\
\text { 354-YILGADPLRV-363 } \\
\text { 309-CRVLCCYVL-317 } \\
\text { 198-(D)ELRRKMMYM-207" } \\
\text { 199-ELKRKMIYM-207" } \\
\text { 279-CVETMCNEY-287 } \\
\text { 379-DEEDAIAAY-387" }\end{array}$ & $\begin{array}{l}\text { HLA-A2 } \\
\text { HLA-A2 } \\
\text { HLA-A2 } \\
\text { HLA-B7 } \\
\text { HLA-B8 } \\
\text { HLA-B18 } \\
\text { HLA-B18 } \\
\text { HLA-B18 }\end{array}$ & $\begin{array}{r}59,146 \\
59 \\
147 \\
57,145 \\
57,145 \\
146 \\
146 \\
146\end{array}$ \\
\hline
\end{tabular}

*Lower case $m$ and upper case $M$ designate open reading frames (ORFs) that are unique to murine cytomegalovirus or homologous to ORFs of human cytomegalovirus, respectively. $\mathrm{m} 18, \mathrm{M} 45$ and $\mathrm{m} 164$ are proteins that are predicted from ORFs, but that have not been biochemically characterized yet. UL describes ORFs in the 'unique long' portion of the human cytomegalovirus genome. The list for human cytomegalovirus includes only peptides for which the optimal length and the MHC class I restriction has been defined. Amino-acid positions are based on the sequence of strain Ad-169. A putative antigenic peptide derived from ORF UL75 (gH) ${ }^{141}$ awaits verification. *Immunodominant peptides of murine cytomegalorvirus are shown in bold type. Sequences refer to strain Smith ATCC VR-194, recently re-accessioned as VR-1399. \$R. Holtappels, unpublished observations. "Peptides derived from a polymorphic region in the human cytomegalovirus IE1 protein. E, early; IE, immediate early; L, late; pp, phosphoprotein.

infected fibroblasts most efficiently during the E phase, when all three immunoevasins are expressed ${ }^{34}$. On the basis of this evidence for the existence of E-phasespecific CTLs in vivo, subsequent studies led to a growing list of antigenic peptides that are derived from mCMV E proteins (TABLE 2). Interestingly, protective CTLs are induced in $\mathrm{mCMV}$-infected $\mathrm{BALB} / \mathrm{c}$ mice by a peptide derived from immunoevasin m04 (REF. 51). This shows that immunoevasins, similar to any other protein, can enter the proteasomal processing pathway and contribute to immune surveillance. So, m04 is a model at the single protein level for the struggle between a virus and its host. For the $\mathrm{H}-2^{\mathrm{d}}$ haplotype, the $\mathrm{CD}^{+} \mathrm{T}$-cell response to $\mathrm{mCMV}$ infection is dominated quantitatively by just two peptides, the IE1-derived peptide that is discussed above (FIG. 1) and a peptide derived from the E-phase protein $\mathrm{m} 164$. Among the $\mathrm{CD}^{+}$effector-memory T-cell population present in the spleen and lungs of latently infected mice, approximately $80 \%$ of the cells were found to be specific for these two peptides ${ }^{52}$, and recent data for the $\mathrm{H}-2^{\mathrm{b}}$ haplotype indicate a similarly focused $\mathrm{CD} 8^{+} \mathrm{T}$-cell response $^{73}$. This immunodominance cannot be explained by clonal selection in vivo by repetitive stimulation with persisting antigens, because the specificity of the response is already shaped in draining lymph nodes shortly after infection $^{52}$. Rather, an intrinsic property of the antigenic proteins or peptides must account for their privileged immunogenicity. 
Although one focus of interest in mCMV immunological research is the identification of antigenic peptides from proteins of the three temporal classes, hCMV immunology is driven by the goal to identify antigenic peptides that are presented by different HLA molecules to achieve whole-population coverage for T-cell-based immunotherapy ${ }^{82}$. At present, the list of antigenic hCMV peptides is expanding on an almost monthly basis (TABLE 2).

There is no rationale for excluding subdominant peptides as vaccine candidates. Subdominant peptides induce protective immunity after DNA vaccination ${ }^{83}$, and CTL lines specific for subdominant peptides resolve infection after adoptive transfer ${ }^{84}$. Together, the list of antigenic peptides (TABLE 2) is an impressive indication of the 'leakiness' of viral immune-evasion mechanisms.
Presentation before immunoevasingene expression. The question remains how MHC class-I-restricted antigenic peptides avoid or overcome the inhibitory effects of the immunoevasins. One answer - which is valid for some, but not all, antigens - is that processing and presentation of the peptide can occur before the immunoevasin genes are expressed. Early data from the mouse model ${ }^{42,43}$, which have been revisited recently ${ }^{84}$, showed that virion proteins render fibroblasts susceptible to lysis by CTLs in the absence of viral gene expression. For hCMV, this mechanism applies to ppUL83 (pp65), which is one of the main sources of antigenic peptides (TABLE 2). It is a virion tegument protein and a main component of the enveloped subviral particles, known as dense bodies, that are delivered into the cytosol through the entry process. Therefore, ppUL83 gains access to the antigen-processing

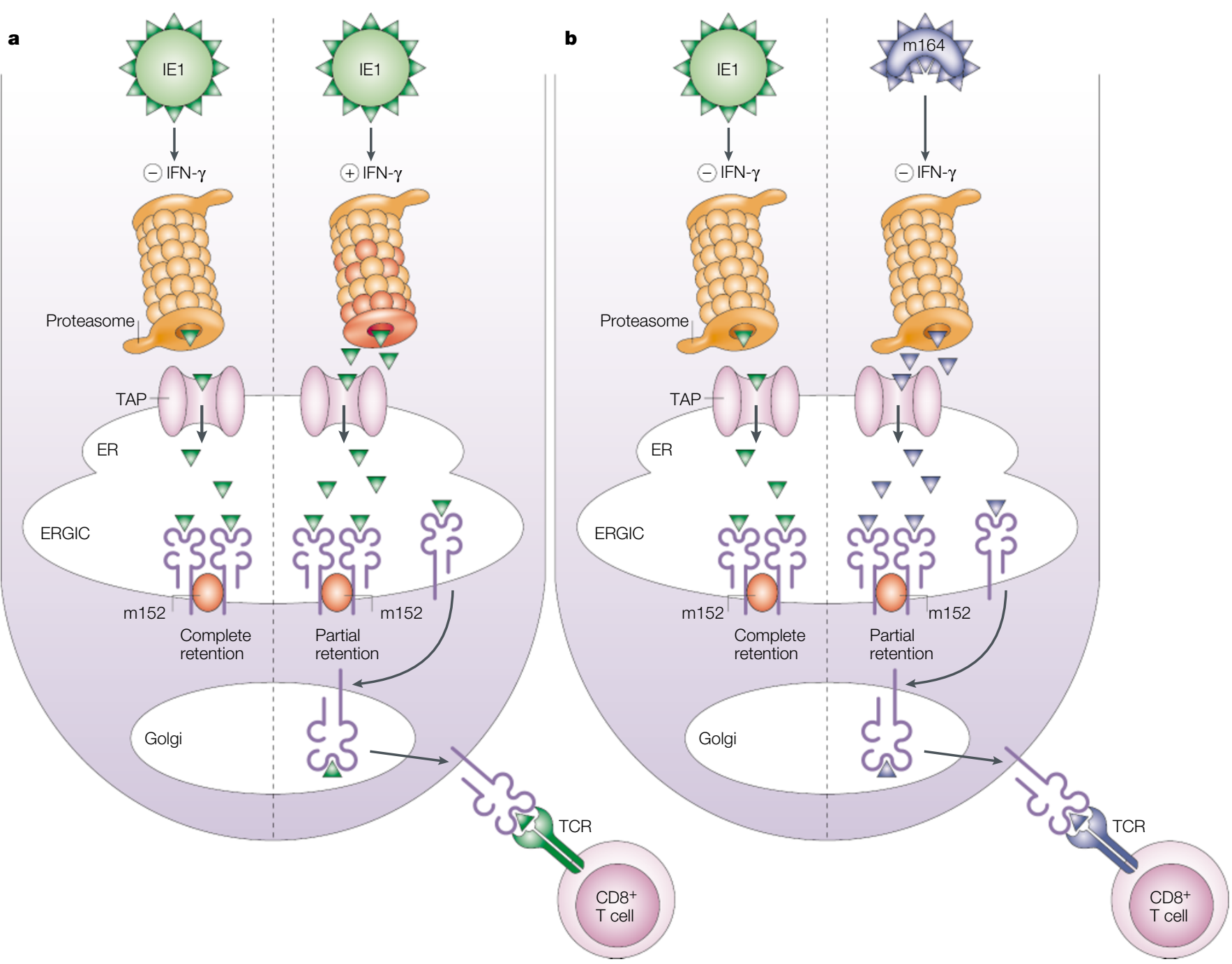

Figure 4 | Proposed mechanisms by which antigens evade immunoevasins. a | Conditional peptide presentation induced by interferon- $\gamma$ (IFN- $\gamma$ ). In the early $(E)$ phase (left-hand side), murine cytomegalovirus ( $\mathrm{MCMV}$ IE1 protein is processed, but presentation of the IE1 peptide is prevented by m152-triggered retention of

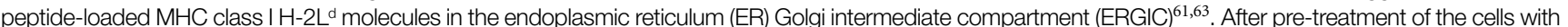
IFN- $\gamma$ (right-hand side), enhanced processing of the IE1 peptide by the immunoproteasome ${ }^{123}$, most probably combined with upregulation of expression of $\mathrm{MHC}$ class I molecules and of the transporter for antigen processing (TAP), leads to the escape of sufficient IE1-H-2L ${ }^{d}$ complexes for recognition by IE1-peptide-specific cytotoxic T lymphocytes (CTLs) at the cell surface ${ }^{100} . \mathbf{b} \mid$ Constitutive peptide presentation. There are viral peptides for which presentation in the presence of immunoevasins does not require IFN- $\gamma^{34,42,72}$. A peptide derived from $\mathrm{mCMV} \mathrm{E-phase} \mathrm{protein} \mathrm{m} 164$, a putative glycoprotein with two predicted membrane-spanning $\alpha$-helices, is processed during the $\mathrm{E}$ phase in fibroblasts in approximately tenfold excess over the IE1 peptide. Although the IE1 peptide is not presented, the same cells are lysed by CTLs specific for the m164-derived peptide ${ }^{103}$. TCR, T-cell receptor. 
pathway before viral gene expression ${ }^{85,86}$ (for a review, see REF. 2). This 'exogenous loading' of the MHC class I pathway might also explain the antigenicity of ppUL32 (pp150), another main constituent of the virion tegument ${ }^{87}$. By contrast, IE1 proteins of hCMV and mCMV are regulatory proteins that are not incorporated in the virion. For mCMV infection, the presentation of the IE1 peptide can be explained by the kinetics of gene expression, because all three immunoevasins are E-phase proteins. It is more difficult to explain the antigenicity of hCMV IE1-derived peptides (TABLE 2), because the immunoevasin gpUS3 is an IE protein ${ }^{66}$ and ppUL83 inhibits proteasomal processing of IE1 (REF. 55).

Priming by antigen cross-presentation. The priming of an adaptive immune response requires antigen presentation by antigen-presenting cells (APCs) — in particular, mature DCs. Although DCs can be infected by mCMV and hCMV, infection is associated with the inhibition of maturation and with functional paralysis of DCs, T-cell deletion and T-cell anergy ${ }^{6-8}$. Effective priming can be carried out by mature uninfected DCs that take up and process antigenic proteins derived from infected cells, a mechanism that is known as cross-presentation ${ }^{88-90}$. Cross-presentation has been documented for hCMV ppUL83 (REFS 91,92) and, importantly, also for IE1 (REF. 92). However, multi-organ CMV disease is caused by virus replication in a broad range of stromal and parenchymal cell types, including bone-marrow stromal cells, endothelial cells, myocytes, hepatocytes, pneumocytes, enterocytes, ependymal cells lining the brain ventricles, placental cytotrophoblasts and various types of glandular epithelial cell ${ }^{20,93,94}$. $\mathrm{CD}^{+} \mathrm{T}$ cells can resolve an established organ infection ${ }^{19,30,95}$. In the BMT model, mCMV replication in tissues precedes the infiltration of protective $\mathrm{CD} 8^{+}$ $\mathrm{T}_{\text {cells }} \mathrm{s}^{21,34,35}$. This clearly implies that antigenic peptides are presented by non-APC tissue cells for CTL effector function in vivo. As discussed recently by Gold et al. ${ }^{73}$, priming by cross-presentation of peptides that are not presented in cells relevant to CMV disease might 'fool' the immune system by the induction of a useless response.

Dependence on the target cell. The many cell types that are implicated in CMV disease should remind us of the limitations of immune-evasion studies that are carried out in cell culture. First of all, cell-culture models of CMV replication exist for a few cell types only, and viral gene expression in growing primary cells or in transformed cell lines is likely to differ from that in the same cell type in the physiological context of tissue. MHC class I downmodulation, which is a hallmark of immunoevasin function, was described originally for fibroblasts, but it has also been found for hCMV with a panel of epithelial-tumour cell lines ${ }^{96}$. The inhibition of $\mathrm{H}-2 \mathrm{~L}^{\mathrm{d}}$ restricted mCMV IE1 peptide presentation by immunoevasin $\mathrm{m} 152$ is tight during the $\mathrm{E}$ phase in fibroblasts, whereas infected macrophages do present this peptide in the E phase ${ }^{97}$, which is important in view of the fact that macrophages are crucially involved in virus dissemination to target organs $s^{98,99}$. However, this cell-type difference does not hold true for an $\mathrm{H}-2 \mathrm{D}^{\mathrm{b}}$-restricted M45-derived peptide of $\mathrm{mCMV}^{73}$. This example shows that the efficacy of immunoevasins is multivariate, and we are far from knowing all of the variables.

Conditional and constitutive peptide presentation. One key to understanding peptide presentation in the face of immunoevasins is the effect of the pro-inflammatory cytokine interferon- $\gamma$ (IFN- $\gamma$ ) on several components of the processing and presentation machinery (FIG. 4a). The IE1 peptide of mCMV provided the first example of IFN- $\gamma$-based conditional peptide presentation in the $E$ phase $e^{100,101}$. For hCMV, in addition to its other effects, IFN- $\gamma$ enhances peptide translocation into the endoplasmic reticulum by blocking the synthesis of immunoevasin gpUS6 (REF. 102). However, there are peptides for which presentation is not rescued by pretreatment of cells with IFN- $\gamma$. Again, mCMV M45 is an example ${ }^{73}$.

Also, as noted earlier in this review, CTLs isolated from pulmonary infiltrates during $\mathrm{mCMV}$ pneumonia lysed fibroblasts in the E phase independent of IFN- $\gamma^{34}$. The existence of peptides that evade the function of immunoevasins constitutively even in fibroblasts was indicated by earlier work by Del Val et al. ${ }^{72}$. One such peptide has now been identified molecularly as being derived from the mCMV E protein m164 (REF. 103) (FIG. 4b).

\section{Virus latency and recurrence}

Mechanisms of immune control eventually gain superiority, resolve productive infection of tissues and prevent CMV disease. That is why we are still alive. However, CMVs would not have acquired such a sophisticated system of immune-evasion mechanisms if they did not confer an advantage in terms of natural selection. After viral replication has stopped, CMVs remain latent in the host under continual surveillance by $\mathrm{CD}^{+} \mathrm{T}$ cells ${ }^{104,105}$, until a weakness of the immune system gives the virus a chance to reactivate ${ }^{106}$. In the mCMV model, it has been shown that the level of replication during acute infection determines the amount of latent viral DNA and the risk of virus recurrence ${ }^{107,108}$. So, by reducing the efficacy of immune control during the productive phase of the infection, immunoevasins might help the virus to establish a high genome load in latently infected tissues. Likewise, during reactivated gene expression, immunoevasins might increase the probability that the virus will complete the replication cycle for productive infection and transmission to another individual. The immunoevasin gene-deletion mutants of mCMV that are available now ${ }^{60}$ will clarify the role of immunoevasins in virus recurrence.

\section{Conclusions and future perspectives}

Besides an academic interest in the molecular details of antigen processing and presentation, research on the immune response to CMVs is relevant to a severe disease that affects newborns and immunocompromised patients (BOX 1). Vaccination, in particular of prospective mothers, could prevent the disability of tens of thousands of children annually and, in addition, save costs in health care (BOX 2). What have we learnt in terms of vaccination strategies? 
If, as proposed in most of the recent reviews on CMVs, immunoevasins prevent antigen presentation in infected tissue cells, vaccination aimed at inducing $\mathrm{CD}^{+}$ T-cell-based immunity would make no sense. Recently, Kärre ${ }^{109}$ commented on the cleverness of CMVs in outsmarting the host. Fortunately, as I hope to have shown here, the host is still a bit smarter than CMVs. The good news is that a search for protective antigenic peptides is not made irrelevant by the viral immunoevasins. In my opinion, peptides that are generated efficiently by the constitutive proteasome and evade the immunoevasins are promising candidates for use in a vaccine. A future aim will be to identify more of these peptides and to define the structural basis of their privileged antigenicity.
It is a burning question whether the deletion of immunoevasin genes will generate a superior vaccine virus. Enhanced presentation of antigenic peptides, as well as a broader spectrum of presented peptides, should improve the priming of a protective T-cell response. However, accelerated resolution of mutant virus replication will reduce the total amount of antigen that is available for the priming of $\mathrm{T}$ cells, as well as of $\mathrm{B}$ cells, and this consequence might counteract the advantageous effects of the mutations. Clearly, the immunogenicity of immunoevasin gene-deletion mutants needs to be evaluated experimentally. Again, the mouse model is about to pave the way in this important area of research.
1. van Regenmortel, M. H. V. et al. (eds) in Virus Taxonomy. Seventh Report of the International Committee on Taxonomy of Viruses 203-225 (Academic Press, San Diego, 2000)

2. Reddehase, M. J. The immunogenicity of human and murine cytomegaloviruses. Curr. Opin. Immunol. 12 390-396 (2000).

3. Ploegh, H. Viral strategies of immune evasion. Science $\mathbf{2 8 0}$ 248-253 (1998).

4. Alcami, A. \& Koszinowski, U. H. Viral mechanisms of immune evasion. Immunol. Today 9, 447-455 (2000).

5. Tortorella, D., Gewurz, B. E., Furman, M. H., Schust, D. J. \& Ploegh, H. L. Viral subversion of the immune system. Annu. Rev. Immunol. 18, 861-926 (2000).

6. Andrews, D. M., Andoniou, C. D., Granucci, F., RicciardiCastagnoli, P. \& Degli-Esposti, M. A. Infection of dendritic cells by murine cytomegalovirus induces functiona paralysis. Nature Immunol. 2, 1077-1084 (2001).

7. Raftery, M. J. et al. Targeting the function of mature dendritic cells by human cytomegalovirus: a multilayered viral defense strategy. Immunity 15, 997-1009 (2001).

8. Moutaftsi, M., Mehl, A. M., Borysiewicz, L. K. \& Tabi, Z Human cytomegalovirus inhibits maturation and impairs function of monocyte-derived dendritic cells. Blood $\mathbf{9 9}$ 2913-2921 (2002)

9. Wiertz, E., Hill, A., Tortorella, D. \& Ploegh, H. Cytomegaloviruses use multiple mechanisms to elude the host immune response. Immunol. Lett. 57, 213-216 (1997)

10. Hengel, H., Brune, W. \& Koszinowski, U. H. Immune evasion by cytomegalovirus - survival strategies of a highly adapted opportunist. Trends Microbiol. 6, 190-197 (1998).

11. Hengel, H. \& Koszinowski, U. H. in Herpesviruses and Immunity (eds Bendinelli, M., Friedman, H. \& Medveczky, P.) 247-264 (Plenum, New York, 1998).

12. Hengel, $\mathrm{H}$. et al. Cytomegaloviral control of $\mathrm{MHC}$ class I function in the mouse. Immunol. Rev. 168, 167-176 (1999).

13. Johnson, D. C. \& Hegde, N. R. Inhibition of the MHC class I antigen presentation pathway by human cytomegalovirus. Curr. Top. Microbiol. Immunol. 269, 101-115 (2002).

14. Farrell, H. E., Davis-Poynter, N. J., Andrews, D. M. \& DegliEsposti, M. A. Function of CMV-encoded MHC class I homologues. Curr. Top. Microbiol. Immunol. 269, 131-151 (2002).

15. Braud, V. M., Tomasec, P. \& Wilkinson, G. W. G. Viral evasion of natural killer cells during human cytomegalovirus infection. Curr. Top. Microbiol. Immunol. 269, 117-130 (2002).

16. Mocarski, E. S. Jr. Immunomodulation by cytomegaloviruses: manipulative strategies beyond evasion Trends Microbiol. 10, 332-339 (2002).

17. Pass, R. F. in Fields Virology 4th edn (eds Knipe, D. M. \& Howley, P. M.) 2675-2705 (Lippincott Williams \& Wikins, Philadelphia, 2001).

18. Jonjic, S., Mutter, W., Weiland, F., Reddehase, M. J. \& Koszinowski, U. H. Site-restricted persisten cytomegalovirus infection after selective long-term depletion of CD4+ T lymphocytes. J. Exp. Med. 169, 1199-1212 (1989).

19. Reddehase, M. J. et al. Interstitial murine cytomegalovirus pneumonia after irradiation: characterization of cells that limit viral replication during established infection of the lungs. J. Virol. 55, 264-273 (1985). Pioneering work on $\mathrm{CDB}^{+} \mathrm{T}$-cell-based immunotherapy of CMV disease in the mouse model.
20. Podlech, J., Holtappels, R., Wirtz, N., Steffens, H.-P. \& Reddehase, M.J. Reconstitution of CD8 T cells is essential for the prevention of multiple-organ cytomegalovirus for the prevention of multiple-organ cytomegalovirus histopathology after bone-marl

21. Podlech, J., Holtappels, R., Pahl-Seibert, M.-F., Steffens, H.-P. \& Reddehase, M. J. Murine model of interstitial cytomegalovirus pneumonia in syngeneic bone-marrow transplantation: persistence of protective pulmonary CD8T-cell infiltrates after clearance of acute infection. J. Virol. $\mathbf{7 4}$ 7496-7507 (2000).

This study shows that $\mathrm{CMV}$-specific $\mathrm{CD} 8^{+} \mathrm{T}$ cells are not anergic in situ and resolve productive infection of the lungs.

22. Barry, S. M., Johnson, M. A. \& Janossy, G. Cytopathology or immunopathology? The puzzle of cytomegalovirus pneumonitis revisited. Bone Marrow Transplant. 26, 591-597 (2000).

23. Bukowski, J. F., Woda, B. A. \& Welsh, R. M. Pathogenesis of murine cytomegalovirus infection in natural-killer-celldepleted mice. J. Virol. 52, 119-128 (1984).

24. Scalco, A. A. et al. The effect of the $\mathrm{Cmv}-1$ resistance gene, which is linked to the natural killer cell gene complex, is mediated by natural killer cells. J. Immunol. 149, 581-589 (1992).

25. Salazar-Mather, T. P., Orange, J. S. \& Biron, C. A. Early murine cytomegalovirus (MCMV) infection induces liver natural killer (NK) cell inflammation and protection through macrophage inflammatory protein $1 \alpha(\mathrm{MIP}-1 \alpha)$-dependen pathways. J. Exp. Med. 187, 1-14 (1998)

26. Daniels, K. A. et al. Murine cytomegalovirus is regulated by a discrete subset of natural killer cells reactive with monoclonal antibody to Ly49H. J. Exp. Med. 194, 29-44 (2001).

27. Arase, H., Mocarski, E. S., Campbell, A. E., Hill, A. B. \& Lanier, L. L. Direct recognition of cytomegalovirus by activating and inhibitory NK-cell receptors. Science $\mathbf{2 9 6}$ 1323-1326 (2002).

28. Welsh, R. M., Brubaker, J. O., Vargas-Cortes, M. \& O'Donnell, C. L. Natural killer (NK)-cell response to virus infections in mice with severe combined immunodeficiency. The stimulation of NK cells and the NK-cell-dependent control of virus infections occur independently of T- and B-cell function. J. Exp. Med. 173, 1053-1063 (1991).

29. Lathbury, L. J., Allan, J. E., Shellam, G. R. \& Scalzo, A. A. Effect of host genotype in determining the relative roles of natural killer cells and T cells in mediating protection against murine cytomegalovirus infection. J. Gen. Virol. 77 2605-2613 (1996).

30. Reddehase, M. J. Jonijc, S., Weiland, F., Mutter, W. \& Koszinowski, U. H. Adoptive immunotherapy of murine Koszinowski, $\mathrm{U}$. H. Adoptive immunotherapy of murine cytomegalovirus adrenalitis in the immunocompromised host: $\mathrm{CD} 4$-helper-independent antiviral function of $\mathrm{CD} 8$ -
positive memory T lymphocytes derived from latently positive memory T lymphocytes derived from laten

31. Joniic, S. et al. Antibodies are not essential for the resolution of primary cytomegalovirus infection but limit dissemination of recurrent virus. J. Exp. Med. 179, 1713-1717 (1994).

32. Jonjic, S., Pavic, I., Lucin, P., Rukavina, D. \& Koszinowski, U. H. Efficacious control of cytomegalovirus infection after long-term depletion of CD8 $8^{+}$T lymphocytes. J. Virol. 64 5457-5464 (1990)

33. Polic, B. et al. Lack of MHC class I complex expression has no effect on spread and control of cytomegalovirus infection in vivo. J. Gen. Virol. 77, 217-225 (1996).
34. Holtappels, R. et al. Control of murine cytomegalovirus in the lungs: relative but not absolute immunodominance of the immediate-early 1 nonapeptide during the antiviral cytolytic T-lymphocyte response in pulmonary infiltrates. J. Virol. 72 7201-7212 (1998).

This study showed, for the first time, that $C D 8^{+} T$ cells present in pulmonary infiltrates during interstitial pneumonia are cytolytic effector cells that lyse mCMV-infected target cells in the early (E) phase.

35. Alterio de Goss, M. et al. Control of cytomegalovirus in bone-marrow transplantation chimeras lacking the prevailing antigen-presenting molecule in recipient tissues rests primarily on recipient-derived CD8T cells. J. Virol. 72 , primarily on recipient $7733-7744$ (1998).

36. Reusser, P., Riddell, S. R., Meyers, J. D. \& Greenberg, P. D. Cytotoxic T-lymphocyte response to cytomegalovirus after human allogeneic bone-marrow transplantation: pattern of recovery and correlation with cytomegalovirus infection and disease. Blood 78, 1373-1380 (1991).

37. Riddell, S. R. et al. Restoration of viral immunity in immunodeficient humans by the adoptive transfer of T-cell clones. Science 257, 238-241 (1992). Pioneering work on CD8 ${ }^{+}$T-cell-based Pioneering work on $\mathrm{CDB}^{+} \mathrm{T}$-cell-based
immunotherapy of CMV disease in humans

38. Chee, M. S. et al. Analysis of the protein-coding content of the sequence of human cytomegalovirus strain AD169. Curr. Top. Microbiol. Immunol. 154, 125-169 (1990).

39. Rawlinson, W. D., Farrell, H. E. \& Barrell, B. G. Analysis of the complete DNA sequence of murine cytomegalovirus. J. Virol. 70, 8833-8849 (1996).

40. Mocarski, E. S. \& Courcelle, C. T. in Fields Virology 4th edn (eds Knipe, D. M. \& Howley, P. M.) 2629-2673 (Lippincott Williams \& Wilkins, Philadelphia, 2001).

41. Honess, R. W. \& Roizman, B. Regulation of herpesvirus macromolecular synthesis: sequential transition of polypeptide synthesis requires functional viral polypeptides. Proc. Natl Acad. Sci. USA 72, 1276-1280 (1975).

42. Reddehase, M. J., Keil, G. M. \& Koszinowski, U. H. The cytolytic T-lymphocyte response to the murine cytomegalovirus. II. Detection of virus replication stagespecific antigens by separate populations of in vivo active specific antigens by separate populations of in vivo active
cytolytic T-lymphocyte precursors. Eur. J. Immunol. 14. 56-61 (1984)

43. Reddehase, M. J. \& Koszinowski, U. H. Significance of herpesvirus immediate early gene expression in cellular immunity to cytomegalovirus infection. Nature $\mathbf{3 1 2}$ 369-371 (1984). The first report of the immunogenicity of CMV immediate-early (IE) antigens.

44. Del Val, M. et al. Molecular basis for cytolytic T-lymphocyte recognition of the murine cytomegalovirus immediate-early protein pp89. J. Virol. 62 3965-3972 (1988).

45. Reddehase, M. J., Rothbard, J. B. \& Koszinowski, U. H. A pentapeptide as minimal antigenic determinant for MHC class-I-restricted T lymphocytes. Nature 337, 651-653 (1989).

References 44 and 45 describe the molecular identification of the mCMV IE1 peptide, the first antigenic peptide to be defined for CMVs.

46. Lyons, P. A., Allan, J. E., Carrello, C., Shellam, G. R. \& Scalzo, A. A. Effect of natural sequence variation at the $\mathrm{H}-2 \mathrm{~L}^{\mathrm{d}}$-restricted $\mathrm{CD} 8^{+} \mathrm{T}$-cell epitope of the murine cytomegalovirus ie1-encoded pp89 on T-cell recognition. J. Gen. Virol. 77, 2615-2623 (1996). 
47. Jonjic, S., del Val, M. Keil, G. M., Reddehase, M. J. \& Koszinowski, U. H. A nonstructural viral protein expressed by a recombinant vaccinia virus protects against letha cytomegalovirus infection. J. Virol. 62, 1653-1658 (1988).

48. Del Val, M. et al. Protection against lethal cytomegalovirus infection by a recombinant vaccine containing a single nonameric T-cell epitope. J. Virol. 65, 3641-3646 (1991).

49. Scalzo, A. A. et al. Induction of protective cytotoxic T cells to murine cytomegalovirus by using a nonapeptide and a human-compatible adjuvant (Montanide ISA 720). J. Virol. 69, 1306-1309 (1995)

50. Gonzales-Armas, J. C., Morello, C. S., Cranmer, L. D. \& Spector, D. H. DNA immunization confers protection agains murine cytomegalovirus infection. J. Virol. 70, 7921-7928 (1996)

51. Holtappels, R. et al. The putative natural killer decoy early gene $\mathrm{m04}$ (gp34) of murine cytomegalovirus encodes an antigenic peptide recognized by protective antiviral CD8 T cells. J. Virol. 74, 1871-1884 (2000)

52. Holtappels, R., Thomas, D., Podlech, J. \& Reddehase, M. J. Two antigenic peptides from genes $m 123$ and $m 164$ of murine cytomegalovirus quantitatively dominate CD8 T-cell memory in the $H-2^{d}$ haplotype. J. Virol. 76, 151-164 (2002).

53. Wills, M. R. et al. The human cytotoxic T-lymphocyte (CTL) response to cytomegalovirus is dominated by structural protein pp65: frequency, specificity and T-cell-receptor usage of pp65-specific CTL. J. Virol. 70, 7569-7579 (1996).

54. Gillespie, G. M. A. et al. Functional heterogeneity and high frequencies of cytomegalovirus-specific CD8 ${ }^{+}$ T lymphocytes in healthy seropositive donors. J. Virol. 74 8140-8150 (2000).

55. Gilbert, M. J., Riddell, S. R., Plachter, B. \& Greenberg, P. D. Cytomegalovirus selectively blocks antigen processing and presentation of its immediate-early gene product. Nature 383, 720-722 (1996)

56. Borysiewicz, L. K. et al. Human cytomegalovirus-specific cytotoxic T cells. Relative frequency of stage-specific CTL recognizing the $72-k D$ immediate-early protein and glycoprotein B expressed by recombinant vaccinia viruses. J. Exp. Med. 168, 919-931 (1988). The first report of the immunogenicity of the IE1 protein of $h \mathrm{CMV}$.

57. Kern, F. et al. Target structures of the CD8 ${ }^{+} \mathrm{T}$-cell response to human cytomegalovirus: the 72 -kilodalton major immediate-early protein revisited. J. Virol. 73, 8179-8184 (1999)

58. Gyulai, Z. et. al. Cytotoxic T lymphocyte (CTL) responses to human cytomegalovirus pp65, IE1-exon 4, gB, pp150 and pp28 in healthy individuals: reevaluation of prevalence of IE1-specific CTLs. J. Infect. Dis. 181, 1537-1546 (2000)

59. Khan, N., Cobbold, M., Keenan, R. \& Moss, P. A. Comparative analysis of $\mathrm{CD} 8^{+} \mathrm{T}$-cell responses against human cytomegalovirus proteins pp65 and immediate early 1 shows similarities in precursor frequency, oligoclonality and shows similarities in precursor frequency, oligoclon).
phenotype. J. Infect. Dis. 185, 1025-1034 (2002).

60. Wagner, M., Gutermann, A., Podlech, J., Reddehase, M. J. \& Koszinowski, U. H. MHC class I allele-specific cooperative and competitive interactions between immune evasion proteins of cytomegalovirus. J. Exp. Med. 196, 805-816 (2002)

This study used a complete set of immunoevasin gene-deletion mutants of $\mathrm{MCMV}$ to show the effects of the three known MHC-class-l-targeting immunoevasins in all seven possible combinations.

61. Del Val, M. et al. Cytomegalovirus prevents antigen presentation by blocking the transport of peptide-loaded major histocompatibility complex class I molecules into the medial-Golgi compartment. J. Exp. Med. 176, 729-738 (1992)

62. Thäle, R. et al. Identification of the mouse cytomegalovirus genomic region affecting major histocompatibility complex class I molecule transport. J. Virol. 69, 6098-6105 (1995)

63. Ziegler, H. et al. A mouse cytomegalovirus glycoprotein retains MHC class I complexes in the ERGIC/cis-Golgi compartments. Immunity 6, 57-66 (1997).

64. Ziegler, H., Muranyi, W., Burgert, H.-G., Kremmer, E. \& Koszinowski, U. H. The luminal part of the murine cytomegalovirus glycoprotein gp40 catalyzes the retention of MHC class I molecules. EMBO J. 19, 870-881 (2000). References 61-64 describe the discovery and the molecular mode of action of the first immunoevasin of CMVs.

65. Barnes, P. D. \& Grundy, J. E. Down-regulation of the class I HLA heterodimer and $\beta 2$-microglobulin on the surface of cells infected with cytomegalovirus. J. Gen. Virol. 73 , 2395-2403 (1992).

Early evidence for the intracellular retention of MHC class I complexes in fibroblasts infected with hCMV.

66. Jones, T. R. et al. Human cytomegalovirus US3 impairs transport and maturation of major histocompatibility complex class I heavy chains. Proc. Natl Acad. Sci. USA 93, 11327-11333 (1996)

67. Ahn, K. et al. Human cytomegalovirus inhibits antigen presentation by a sequential multistep process. Proc. Nat Acad. Sci. USA 93, 10990-10995 (1996)

68. Warren, A. P., Ducroq, D. H., Lehner, P. J. \& Borysiewicz, L. K. Human cytomegalovirus-infected cells have unstable assembly of major histocompatibility complex class I complexes and are resistant to lysis by cytotoxic T lymphocytes. J. Virol. 68, 2822-2829 (1994).

69. Wiertz, E. J. H. J. et al. SEC61-mediated transfer of membrane protein from the endoplasmic reticulum to the proteasome for destruction. Nature 384, 432-438 (1996). This study unravels the molecular details of the retrograde translocation of MHC class I molecules for proteasomal degradation, mediated by the hCMV immunoevasin gpUS2

70. Wiertz, E. J. E. J. et al. The human cytomegalovirus US11 gene product dislocates $\mathrm{MHC}$ class I heavy chains from the endoplasmic reticulum to the cytosol. Cell/ 84, 769-779 (1996).

71. van der Wal, F. J., Kikkert, M. \& Wiertz, E. The HCMV gene products US2 and US11 target MHC class I molecules for degradation in the cytosol. Curr. Top. Microbiol. Immunol. 269, 37-56 (2002).

72. Del Val, M., Münch, K., Reddehase, M. J. \& Koszinowski, U. H. Presentation of CMV immediate-early antigen to cytolytic T lymphocytes is selectively prevented by vira genes expressed in the early phase. Cell $\mathbf{5 8}, 305-315$ (1989).

73. Gold, M. et al. The murine cytomegalovirus immunomodulatory gene $m 152$ prevents recognition of infected cells by M45-specific CTL, but does not alter the immunodominance of the M45-specific CD8 T-cell response in vivo. J. Immunol. 169, 359-365 (2002).

74. Krmpotic, A. et al. The immunoevasive function encoded by the mouse cytomegalovirus gene $m 152$ protects the virus against T-cell control in vivo. J. Exp. Med. 190, 1285-1295 (1999).

The first evidence for in vivo attenuation of CMV pathogenicity by deletion of an MHC-class-I-targeting immunoevasin.

75. Krmpotic, A. et al. MCMV glycoprotein gp40 confers virus resistance to CD8 ${ }^{+}$T lymphocytes and NK cells in vivo. Nature Immunol. 3, 529-535 (2002).

Nature first example of an immunoevasin that inhibits The first example of an immunoevasin that inhibits
adaptive and innate immune functions simultaneously. adaptive and innate imm

76. Jones, T. R. et al. Multiple independent loci within the human cytomegalovirus unique short region down-regulate expression of major histocompatibility complex class I heavy chains. J. Virol. 69, 4830-4841 (1995). Pioneering work mapping immunoevasin genes to the unique short region of the $\mathrm{hCMV}$ genome.

77. Kleijnen, M. F. et al. A mouse cytomegalovirus glycoprotein, gi 34 , forms a complex with folded class I MHC molecules in the ER which is not retained but is transported to the cell surface. EMBO J. 16, 685-694 (1997).

78. Kavanagh, D. G., Koszinowski, U. H. \& Hill, A. B. The murine cytomegalovirus immune evasion protein m4/gp34 forms biochemically distinct complexes with class I MHC at the cel surface and in a pre-Golgi compartment. J. Immunol. 167 3894-3902 (2001).

79. Gewurz, B. E., Wang, E. W., Tortorella, D., Schust, D. J. \& Ploegh, H. L. Human cytomegalovirus US2 endoplasmic reticulum-lumenal domain dictates association with major histocompatibility complex class I in a locus-specific manner. J. Virol. 75, 5197-5204 (2001)

80. Rehm, A. et al. Human cytomegalovirus gene products US2 and US11 differ in their ability to attack majo histocompatibility class I heavy chains in dendritic cells. J. Virol. 76, 5043-5050 (2002)

A demonstration of cell-type-specific differences in the hierarchy of immunoevasin functions.

81. Kavanagh, D. G., Gold, M. C., Wagner, M., Koszinowski, U. H. \& Hill, A. B. The multiple immune-evasion genes of murine cytomegalovirus are not redundant: $\mathrm{m} 4$ and $\mathrm{m} 152$ inhibit antigen presentation in a complementary and cooperative fashion. J. Exp. Med. 194, 967-977 (2001). The first report of functional cooperation between The first report o
immunoevasins.

82. Longmate, J. et al. Population coverage by HLA class-Irestricted cytotoxic T-lymphocyte epitopes. Immunogenetics 52, 165-173 (2001)

83. Morello, C. S., Cranmer, L. D. \& Spector, D. H. Suppression of murine cytomegalovirus (MCMV) replication with a DNA vaccine encoding MCMV M84 (a homolog of human cytomegalovirus pp65). J. Virol. 74, 3696-3708 (2000)

4. Holtappels, R. et al. Experimental preemptive immunotherapy of murine cytomegalovirus disease with $\mathrm{CD} 8 \mathrm{~T}$-cell lines specific for ppM83 and pM84, the two homologs of human cytomegalovirus tegument protein ppUL83 (pp65). J. Virol. 75, 6584-6600 (2001). Using different approaches, references 83 and 84 document the protective antiviral potential of subdominant viral peptides.

85. Riddell, S. R., Rabin, M., Geballe, A. P., Britt, W. J. \& Greenberg, P. D. Class I MHC-restricted cytotoxic T lymphocyte recognition of cells infected with human cytomegalovirus does not require endogenous viral gene expression. J. Immunol. 146, 2795-2804 (1991).

86. Pepperl, S., Münster, J., Mach, M., Harris, J. R. \& Plachter, B. Dense bodies of human cytomegalovirus induce both humoral and cellular immune responses in the absence of viral gene expression. J. Virol. 74, 6132-6146 (2000).

87. Jahn, G. et al. Map position and nucleotide sequence of the gene for the large structural phosphoprotein of human cytomegalovirus. J. Virol. 61, 1358-1367 (1987).

88. Sigal, L. J., Crotty, S., Andino, R. \& Rock, K. L. Cytotoxic T-cell immunity to virus-infected non-haematopoietic cells requires presentation of exogenous antigen. Nature $\mathbf{3 9 8}$ 77-80 (1999).

89. Heath, W. R. \& Carbone, F. R. Cross-presentation in viral immunity and self-tolerance. Nature Rev. Immunol. 1, 126-134 (2001).

90. Fonteneau, J.-F, Larsson, M. \& Bhardwaj, N. Interactions between dead cells and dendritic cells in the induction of antiviral CTL responses. Curr. Opin. Immunol. 14, 471-477 (2002).

91. Arrode, G. et al. Incoming human cytomegalovirus pp65 (UL83) contained in apoptotic infected fibroblasts is crosspresented to $\mathrm{CD}^{+} \mathrm{T}$ cells by dendritic cells. J. Virol. $\mathbf{7 4}$, 10018-10024 (2000).

92. Tabi, Z., Moutaftsi, M. \& Borysiewicz, L. K. Human cytomegalovirus pp65- and immediate early 1 antigenspecific HLA class-I-restricted cytotoxic T-cell responses induced by cross-presentation of viral antigens. J. Immunol. 166, 5695-5703 (2001).

93. Plachter, B., Sinzger, C. \& Jahn, G. Cell types involved in replication and distribution of human cytomegalovirus. Adv. Virus Res. 46, 195-261 (1996)

94. Fisher, S., Genbacev, O., Maidji, E. \& Pereira, L. Human cytomegalovirus infection of placental cytotrophoblasts in vitro and in utero: implications for transmission and pathogenesis. J. Virol. 74, 6808-6820 (2000).

95. Reddehase, M. J., Mutter, W. \& Koszinowski, U. H. In vivo application of recombinant interleukin-2 in the immunotherap of established cytomegalovirus infection. J. Exp. Med. 165 , 650-656 (1987).

96. Benz, C. et al. Efficient downregulation of major histocompatibility complex class I molecules in human epithelial cells infected with cytomegalovirus. J. Gen. Virol. 82, 2061-2070 (2001).

97. Hengel, H. et al. Macrophages escape inhibition of major histocompatibility complex class I-dependent antigen presentation by cytomegalovirus. J. Virol. 74, 7861-7868 (2000)

98. Stoddard, C. A. et al. Peripheral-blood mononuclear phagocytes mediate dissemination of murine cytomegalovirus. J. Virol. 68, 6243-6253 (1994).

99. Hanson, L. K. et al. Replication of murine cytomegalovirus in differentiated macrophages as a determinant of viral pathogenesis. J. Virol. 73, 5970-5980 (1999).

100. Hengel, H., Lucin, P., Jonjic, S., Ruppert, T. \& Koszinowski, U. H. Restoration of cytomegalovirus antigen presentation by $\gamma$-interferon combats viral escape. J. Virol. 68, 289-297 (1994)

101. Geginat, G., Ruppert, T., Hengel, H., Holtappels, R. \& Koszinowski, $U$. H. IFN- $\gamma$ is a prerequisite for optimal antigen processing of viral peptides in vivo. J. Immunol. 158, 3303-3310 (1997).

References 100 and 101 provide evidence in vitro and in vivo of a role for IFN- $\gamma$ in the restoration of antigen presentation in the presence of immunoevasins.

102. Benz, C. \& Hengel, H. MHC class-I-subversive gene functions of cytomegalovirus and their regulation by interferons - an intricate balance. Virus Genes 21, 39-47 (2000).

103. Holtappels, R. et al. Processing and presentation of murine cytomegalovirus pORFm 164-derived peptide in fibroblasts in the face of all viral immunosubversive early gene functions. J. Virol. 76, 6044-6053 (2002). Identification of an E-phase peptide of $\mathrm{mCMV}$ that constitutively escapes all immunoevasin functions.

104. Polic, B. et al. Hierarchical and redundant lymphocyte subset control precludes cytomegalovirus replication during latent infection. J. Exp. Med. 188, 1047-1054 (1998).

105. Holtappels, R., Pahl-Seibert, M.-F., Thomas, D. \& Reddehase, M. J. Enrichment of immediate-early 1 (m123/pp89) peptide-specific CD8 T cells in a pulmonary CD62L-lo memory-effector cell pool during latent murin cytomegalovirus infection of the lungs. J. Virol. $\mathbf{7 4}$ 11495-11503 (2000). 
106. Kurz, S. K. \& Reddehase, M. J. Patchwork pattern of transcriptional reactivation in the lungs indicates sequential checkpoints in the transition from murine cytomegaloviru latency to recurrence. J. Virol. 73, 8612-8622 (1999).

107. Reddehase, M. J. et al. The conditions of primary infection define the load of latent viral genome in organs and the risk of recurrent cytomegalovirus disease. J. Exp. Med. 179, 185-193 (1994).

108. Steffens, H.-P., Kurz, S., Holtappels, R. \& Reddehase, M. J. Preemptive CD8-T-cell immunotherapy of acute cytomegalovirus infection prevents lethal disease, limits the burden of latent viral genome and reduces the risk of virus recurrence. J. Virol. 72, 1797-1804 (1998).

109. Kärre, K. Clever, cleverer, cleverest. Nature Immunol. 3, 505-506 (2002).

110. Jahn, G., Pohl, W., Plachter, B. \& von Hintzenstern, J. Congenital cytomegalovirus infection with fatal outcome. Dtsch. Med. Wochenschr. 113, 424-427 (1988).

111. Boppana, S. B., Rivera, L. B., Fowler, K. B., Mach, M. \& Britt, W. J. Intrauterine transmission of cytomegalovirus to infants of women with preconceptional immunity. N. Engl. J. Med. 344, 1366-1371 (2001).

112. Ho, M. Cytomegalovirus. Biology and Infection (Plenum Medical Book Company, New York and London, 1982).

113. Britt, W. J. Vaccines against human cytomegalovirus: time to test. Trends Microbiol. 4, 34-38 (1996).

114. Gonczol, E. \& Plotkin, S. Development of a cytomegalovirus vaccine: lessons from recent clinical trials. Exp. Opin. Biol. Ther. 1, 401-412 (2001).

115. Stratton, K. R., Durch, J. S. \& Lawrence, R. S. (eds) Vaccines for the 21st Century. A Tool for Decisionmaking. Committee to Study Priorities for Vaccine Development (Division of Health Promotion and Disease Prevention, Institute of Medicine, The National Academies, Washington, 2001).

Arguments in favour of a vaccine against hCMV (see Further Information).

116. Dorsch-Häsler, K. et al. A long and complex enhancer activates transcription of the gene coding for the highly abundant immediate-early mRNA in murin cytomegalovirus. Proc. Natl Acad. Sci. USA 82, 8325-8329 (1985)

117. Keil, G. M., Ebeling-Keil, A. \& Koszinowski, U. H. Sequence and structural organization of murine cytomegalovirus immediate-early gene 1. J. Virol. 61, 1901-1908 (1987).

118. Messerle, M., Keil, G. M. \& Koszinowski, U. H. Structure and expression of murine cytomegalovirus immediate-early gene 2. J. Virol. 65, 1638-1643 (1991).

119. Messerle, M. Bühler, B., Keil, G. M. \& Koszinowski, U. H. Structural organization, expression and functional characterization of the murine cytomegalovirus immediateearly gene 3. J. Virol. 66, 27-36 (1992).

120. Gribaudo, G. et al. Murine cytomegalovirus stimulates cellular thymidylate synthase gene expression in quiescent cells and requires the enzyme for replication. J. Virol. $\mathbf{7 4}$ 4979-4987 (2000).

121. Cardin, R. D., Abenes, G. B., Stoddart, A. \& Mocarski, E. S. Murine cytomegalovirus IE2, an activator of gene expression, is dispensable for growth and latency in mice. Virology 209, 236-241 (1995).

122. Angulo, A., Ghazal, P. \& Messerle, M. The major immediateearly gene ie3 of mouse cytomegalovirus is essential for vira growth. J. Virol. 74, 11129-11136 (2000).

123. Knuehl, C. et al. The murine cytomegalovirus pp89 immunodominant $\mathrm{H}-2 \mathrm{~L}^{\mathrm{d}}$ epitope is generated and translocated into the endoplasmic reticulum as an 11-mer precursor peptide. J. Immunol. 167, 1515-1521 (2001). This paper describes the molecular details of $\mathrm{mCMV}$ IE1 processing and peptide translocation into the endoplasmic reticulum.
124. Serwold, T., Gonzales, F., Kim, J., Jacob, R. \& Shastri, N. ERAAP customizes peptides for MHC class I molecules in the endoplasmic reticulum. Nature $\mathbf{4 1 9}, 480-483$ (2002).

125. Shastri, N., Schwab, S. \& Serwold, T. Producing nature's gene-chips. The generation of peptides for display by MHC class I molecules. Annu. Rev. Immunol. 20, 463-493 (2002).

126. Rammensee, H.-G., Bachmann, J. \& Stevanovic, S. MHC Ligands and Peptide Motifs (Molecular Biology Intelligence Unit, Landes Bioscience, Austin, Texas, 1997).

127. Reddehase, M. J. \& Koszinowski, U. H. Redistribution of critical major histocompatibility complex and T-cell receptorbinding functions of residues in an antigenic sequence after biterminal substitution. Eur. J. Immunol. 21, 1687-1701 (1991).

128. Reusch, U. et al. A cytomegalovirus glycoprotein re-routes $\mathrm{MHC}$ class I complexes to lysosomes for degradation. EMBO J. 18, 1081-1091 (1999).

129. Ahn, K. et al. The ER-luminal domain of the HCMV glycoprotein US6 inhibits peptide translocation by TAP. Immunity 6, 613-621 (1997)

130. Hengel, H. et al. A viral ER-resident glycoprotein inactivates the $\mathrm{MHC}$-encoded peptide transporter. Immunity 6, 623-632 (1997)

131. Lehner, P. J., Karttunen, J. T., Wilkinson, G. W. G. \& Cresswell, P. The human cytomegalovirus US6 glycoprotein inhibits transporter associated with antigen processingdependent peptide translocation. Proc. Natl Acad. Sci. USA 94, 6904-6909 (1997)

References 129-131 describe the discovery and mode of action of hCMV immunoevasin gpUS6, the first immunoevasin to be discovered that targets TAP-dependent peptide translocation into the endoplasmic reticulum.

132. Gewurz, B. E. et al. Antigen presentation subverted: structure of the human cytomegalovirus protein US2 bound to the class I molecule HLA-A2 Proc. Natl Acad. Sci. USA to the class I molecule The crystal structure of hCMV immunoevasin gpUS2 bound to HLA-A2

133. Holtappels, R., Grzimek, N. K. A., Thomas, D. \& Reddehase, M. J. Early gene $m 18$, a novel player in the immune response to murine cytomegalovirus. J. Gen. Virol. 83, 311-316 (2002).

134. Holtappels, R., Thomas, D. \& Reddehase, M. J. Identification of a $K^{d}$-restricted antigenic peptide encoded by murine cytomegalovirus early gene M84. J. Gen. Virol. 81 3037-3042 (2000).

135. Utz, U., Koenig, S., Coligan, J. E. \& Biddison, W. E. Presentation of three different viral peptides, HTLV-1 Tax, $\mathrm{HCMV} \mathrm{gB}$ and influenza virus M1, is determined by common structural features of the HLA-A2.1 molecule. J. Immunol. 149, 214-221 (1992)

136. Parker, K. C. et al. Sequence motifs important for peptide binding to the human MHC class I molecule, HLA-A2. J. Immunol. 149, 3580-3587 (1992).

137. Hebart, H. et al. Sensitive detection of human cytomegalovirus peptide-specific cytotoxic T-lymphocyte cytomegalovirus peptide-specific cytotoxic T-lymphocy
responses by interferon- $\gamma$-enzyme-linked immunospot assay and flow cytometry in healthy individuals and in patients after allogeneic stem-cell transplantation. Blood $\mathbf{9 9}$ patients after allogen

138. Solache, A. et al. Identification of three HLA-A*0201restricted cytotoxic T-cell epitopes in the cytomegalovirus protein pp65 that are conserved between eight strains of the virus. J. Immunol. 163, 5512-5518 (1999).

139. Diamond, D. J., York, J., Sun, J. Y., Wright, C. L. \& Forman, S. J. Development of a candidate HLA A*0201-restricted peptide-based vaccine against human cytomegalovirus infection. Blood 90, 1751-1767 (1997).
140. Masuoka, M. et al. Identification of the HLA-A24 peptide epitope within cytomegalovirus protein pp65 recognized by CMV-specific cytotoxic T lymphocytes. Viral Immunol. 14, 369-377 (2001).

141. Kuzushima, K., Hayashi, N., Kimura, H. \& Tsurumi, T. Efficient identification of $\mathrm{HLA}-\mathrm{A}^{\star} 2402$-restricted cytomegalovirus-specific CD8 ${ }^{+} \mathrm{T}$-cell epitopes by a computer algorithm and an enzyme-linked immunospot assay. Blood 98, 1872-1881 (2001).

142. Weekes, M. P., Wills, M. R., Mynard, K., Carmichael, A. J. \& Sissons, J. G. P. The memory cytotoxic T-lymphocyte response to human cytomegalovirus infection contains individual peptide-specific CTL clones that have undergon individual peptide-specifo CTL Clones that have undergone

143. Kern, F. et al. T-cell epitope mapping by flow cytometry. Nature Med. 4 975-978 (1998)

144. Gavin, M. A., Gilbert, M. J., Riddell, S. R., Greenberg, P. D. \& Bevan, M. J. Alkali hydrolysis of recombinant proteins allows for the rapid identification of class I MHC-restricted CTL epitopes. J. Immunol. 151, $3971-3980$ (1993).

145. Wills, M. R. et al. Identification of naive or antigenexperienced human $C D 8^{+} T$ cells by expression of costimulation and chemokine receptors: analysis of the human cytomegalovirus-specific CD8 ${ }^{+} \mathrm{T}$-cell response. J. Immunol. 168, 5455-5464 (2002).

146. Retiere, C. et al. Generation of cytomegalovirus-specific human T-lymphocyte clones by using autologous B-lymphoblastoid cells with stable expression of pp65 or IE 1 proteins: a tool to study the fine specificity of the antiviral response. J Virol. 74, 3948-3952 (2000).

147. Frankenberg, N., Pepperl-Klindworth, S., Meyer, R. G. \& Plachter, B. Identification of a conserved HLA-A2-restricted decapeptide from the IE1 protein ( $\mathrm{pUL123)}$ ) f human cytomegalovirus. Virology 295, 208-216 (2002)

148. Grzimek, N. K. A. et al. In vivo replication of recombinant murine cytomegalovirus driven by the paralogous major immediate-early enhancer of human cytomegalovirus.

J. Virol. 73, 5043-5055 (1999).

Acknowledgements

I apologize to all colleagues whose publications have not been included owing to space constraints and the focus of the review. I also apologize to colleagues who might have published peptide sequences (TABLE 2) that did not come to my attention. I thank U. H. Koszinowski, who brought me into CMV research and who was my scientific mentor for many years. I greatly appreciate the advice given by R. S. Lawrence regarding BOX 2, and by P.-M. Kloetzel, H.-G. Rammensee and N. Shastri regarding FIG. 1. My co-workers J. Podlech and C. O. Simon did a perfect job with the design of the figures. Our recent work has been funded by the Deutsche Forschungsgemeinschaft.

\section{(1) Online links}

\section{DATABASES}

The following terms in this article are linked online to:

Entrez: http://www.ncbi.nlm.nih.gov/entrez/query.fcg

hCMV | IE1 | m152 | mCMV | rat cytomegalovirus

LocusLink: http://www.ncbi.nlm.nih.gov/LocusLink IFN- $\gamma \mid$ TAP1 | TAP2

\section{FURTHER INFORMATION}

Institute of Medicine: http://www.iom.edu/

Vaccines for the 21st Century: A Tool for Decision-Making:

http://stills.nap.edu/books/0309056462/html/

SYFPEITHI Database for MHC-Binding Motifs:

http://mww. syfpeithi.de

Institute for Virology, Johannes Gutenberg-University:

http://www.virologie.medizin.uni-mainz.de/

Access to this interactive links box is free online. 